\title{
Characterization of Epidermal Bladder Cells in Chenopodium quinoa
}

Sophie Otterbach ${ }^{1}$, Holly Khoury ${ }^{2}$, Thusitha Rupasinghe ${ }^{3}$, Himasha Mendis ${ }^{2}$, Kim Kwan ${ }^{4}$, Veronica Lui ${ }^{4}$, Siria Natera ${ }^{4}$, Iris Klaiber ${ }^{5}$, Nathaniel Allen ${ }^{1}$, David Jarvis ${ }^{6}$, Mark Tester ${ }^{7}$, Ute Roessner $^{8}$, and Sandra Schmöckel ${ }^{1}$

${ }^{1}$ University of Hohenheim Faculty of Agricultural Sciences

${ }^{2}$ University of Melbourne School of BioSciences

${ }^{3}$ University of Melbourne

${ }^{4}$ The University of Melbourne

${ }^{5}$ University of Hohenheim

${ }^{6}$ Brigham Young University

${ }^{7}$ King Abdullah University of Science and Technology

${ }^{8}$ School of Botany

May 10, 2021

\begin{abstract}
Chenopodium quinoa (quinoa) is considered a superfood, as it has favourable nutrient composition and is gluten free. Quinoa has high tolerance to several abiotic stresses, i.e. salinity, water deficit (drought) and cold. The tolerance mechanisms are yet to be elucidated. Quinoa has Epidermal Bladder Cells (EBCs) that densely cover the shoot surface, particularly the younger parts of the plant. Here, we report on the EBC's primary and secondary metabolomes, as well as the lipidome in response to abiotic stresses. EBCs were isolated from plants after cold, heat, high-light, water deficit and salt treatments. We used untargeted Gas Chromatography-Mass Spectrometry (GC-MS) to analyse metabolites and untargeted and targeted Liquid Chromatography-MS (LC-MS) for lipids and secondary metabolite analyses. We identified 64 primary metabolites, including sugars, organic acids and amino acids, 19 secondary metabolites, including phenolic compounds, betanin and saponins and 240 lipids categorized in five groups including glycerolipids and phospholipids. Although we found only few changes in the metabolic composition of bladders in response to abiotic stresses, metabolites related with heat, cold and high-light treatments, but not salt stress, were changed significantly. $\mathrm{Na}^{+}$concentrations were low in EBCs with all treatments, and approximately two orders of magnitude lower than $\mathrm{K}^{+}$concentrations.
\end{abstract}

\section{Title}

Characterization of Epidermal Bladder Cells in Chenopodium quinoa

\section{Authors}

Sophie Otterbach ${ }^{1}$, Holly Khoury ${ }^{2}$, Thusitha Rupasinghe ${ }^{2}$, Himasha Mendis ${ }^{2}$, Kim H. Kwan ${ }^{3}$, Veronica Lui ${ }^{3}$, Siria H. A. Natera ${ }^{3}$, Iris Klaiber ${ }^{4}$, Nathaniel M. Allen ${ }^{1}$, David E. Jarvis ${ }^{5}$, Mark Tester ${ }^{3}$, Ute Roessner ${ }^{2,{ }^{*}}$, Sandra M. Schmöckel ${ }^{1, *}$

\section{Affiliations/Contact Information}

${ }^{1}$ Department of Crop Science, Faculty of Agriculture, University of Hohenheim, 70599 Stuttgart, Germany 
${ }^{2}$ School of BioSciences, The University of Melbourne, Victoria 3010, Australia

${ }^{3}$ Metabolomics Australia, The University of Melbourne, Victoria 3010, Australia

${ }^{4}$ King Abdullah University of Science and Technology, Thuwal 23955, Saudi Arabia

${ }^{5}$ Core Facility Hohenheim (640). Mass Spectrometry Unit, University of Hohenheim, Stuttgart, Germany

${ }^{6}$ Brigham Young University, Department of Plant and Wildlife Sciences, College of Life Sciences, Provo, Utah 84602, USA

* Roessner and Schmöckel should be considered joint senior author.

\title{
Join Corresponding Author Details
}

\section{Ute Roessner}

School of BioSciences, The University of Melbourne, Victoria 3010, Australia

Email: u.roessner@unimelb.edu.au

Tel: +61390353635

\section{Sandra M. Schmöckel}

Institute of Crop Science, Department Physiology of Yield Stability, University of Hohenheim, 70599 Stuttgart, Germany

Email: sandra.schmoeckel@uni-hohenheim.de

Tel: +4971145923806

\begin{abstract}
Chenopodium quinoa (quinoa) is considered a superfood, as it has favourable nutrient composition and is gluten free. Quinoa has high tolerance to several abiotic stresses, i.e. salinity, water deficit (drought) and cold. The tolerance mechanisms are yet to be elucidated. Quinoa has Epidermal Bladder Cells (EBCs) that densely cover the shoot surface, particularly the younger parts of the plant. Here, we report on the EBC's primary and secondary metabolomes, as well as the lipidome in response to abiotic stresses. EBCs were isolated from plants after cold, heat, high-light, water deficit and salt treatments. We used untargeted Gas Chromatography-Mass Spectrometry (GC-MS) to analyse metabolites and untargeted and targeted Liquid Chromatography-MS (LC-MS) for lipids and secondary metabolite analyses. We identified 64 primary metabolites, including sugars, organic acids and amino acids, 19 secondary metabolites, including phenolic compounds, betanin and saponins and 240 lipids categorized in five groups including glycerolipids and phospholipids. Although we found only few changes in the metabolic composition of bladders in response to abiotic stresses, metabolites related with heat, cold and high-light treatments, but not salt stress, were changed significantly. $\mathrm{Na}^{+}$concentrations were low in EBCs with all treatments, and approximately two orders of magnitude lower than $\mathrm{K}^{+}$concentrations.
\end{abstract}

\section{Keywords}

Chenopodium quinoa, epidermal bladder cells, EBC, abiotic stress, metabolomics, lipidomics

\section{Introduction}

The global demand for crops is continuing to increase (FAO, 2018). Additionally, declining arable land and altering climate conditions make this demand harder to satisfy. Abiotic stresses are a major limiting factor to agricultural production (FAO, 2018). It is therefore key that agricultural expansion include the improvement of crops for abiotic stress tolerance and utilize crop diversity (Tanksley \& McCouch, 1997). 
Quinoa (Chenopodium quinoa Willd.) is a pseudocereal and a major Andean crop that is adapted to a broad range of agro-ecological conditions and abiotic stresses, including soil salinity, drought and cold (Zurita-Silva et al., 2014). Quinoa is considered a halophyte because it has a high salinity tolerance and can grow in soils which have been treated with $\mathrm{NaCl}$ concentrations as high as seawater (Roman et al., 2020). Quinoa seed has recently gained much attention because of its nutritional value and adaptations to marginal environments. Quite noticeable is that the epidermal surface is covered in small bladders, including the abaxial and adaxial leaf sides, petioles, stem and the flower cluster (panicle) (Fig. 1 ). However, the role of these bladders remains inconclusive. Plants interact with their environment through their epidermis, which has a wide variety of functional specializations and epidermal structural adaptations for defence against pests and diseases. One of these adaptions are trichomes made of single or multiple cells, covering the surface of leaves, petals, stems, petioles, peduncles, and seeds depending on the species (Wagner, 1991). It has been reported that some halophytes have developed specialized trichomes to adapt to high salinity, for instance by secreting salts through salt glands or sequestration of salts into salt bladders (Adams et al., 1998; Liphschitz \& Waisel, 1982). Salt bladders are usually composed of an epidermal cell, one to two stalk cells and an epidermal bladder cell (enlarged vacuolated cell). Mesembryanthemum crystallinum is a model halophyte used to measure $\mathrm{Na}^{+}$accumulation and osmotic homoeostasis in their epidermal bladder cells (EBCs) (Barkla et al., 2012).

EBCs are large vacuolated cells with or without stalk cells and are mainly present in Aizoaceae and Amaranthaceae (Adams et al., 1998; Agarie et al., 2007; Karimi \& Ungar, 1989). These EBCs are very flexible and can expand to accumulate high concentrations of salt, like in the vacuoles of M. crystallinum of up to 1 M (Adam \& Zapp, 1998; Barkla et al., 2002). The EBCs of M. crystallinumhave been extensively researched to investigate the role of these cells. Protein profiling showed diverse proteins involved in $\mathrm{H}^{+}$-transport, primary metabolism and crassulacean acid metabolism (CAM) (Barkla et al., 2012, 2016; Jou et al., 2007). Analyses of the metabolic composition of the EBCs has revealed that these cells are metabolically active. A comparative study of salt-treated and control M. crystallinum EBCs identified over 300 significantly differing metabolites accounting for 13 biochemical pathways and mainly classified as compatible solutes (sugars, amino acids, organic acids) to maintain osmotic homeostasis (Barkla \& Vera-Estrella, 2015). Stress responses in the EBCs have also been induced by high UV radiation, where it was suggested that increased flavonoid and betacyanin concentrations protect the leaves from strong irradiation (Ibdah et al., 2002; Oh et al., 2015; Vogt et al., 1999).

In quinoa, however, the EBCs are much smaller compared to $M$. crystallinum and do not enlarge over time (Orsini et al., 2011). In quinoa, EBCs have been hypothesized to mediate salinity tolerance by storing $\mathrm{K}^{+}$, storing $\mathrm{Na}^{+}$, reducing water loss, preventing UV damage by acting as a 'secondary' epidermis and acting as metabolite storage (Adolf et al., 2013; Kiani-Pouya et al., 2017; LoPresti, 2014; Shabala et al., 2012). Transcriptome analysis of EBCs identified candidate genes possibly involved in salt tolerance, as well as abiotic stress responses and cell wall synthesis (Böhm et al., 2018; Zou et al., 2017). However, a recent study shows that $\mathrm{Na}^{+}$concentrations in the EBCs did not increase substantially in the EBCs of salt stressed quinoa to account for the amount of ions in the leaves (Roman et al., 2020). The EBCs of quinoa exhibit a unique transcriptomic profile with over 5000 differently expressed genes compared to the epidermal cells of the leaves, suggesting a high metabolic activity in these cells (Böhm et al., 2018; Zou et al., 2017).

To gain more insights on the role of the EBCs we conducted a metabolic study on quinoa's EBCs in response to several abiotic stresses: salinity, water deficit, heat, cold and high-light. Acquiring a metabolomic profile of quinoa's EBCs required a combination of liquid chromatography (LC) and gas chromatography (GC) coupled with mass spectrometry (MS) for metabolite and lipid profiling. We also combined two approaches to couple selectivity and sensitivity for an encompassing metabolome analysis: targeted and untargeted. Plant metabolomics research is a complex endeavour and depends largely on the instrumentation to comprehensively quantify and localize metabolites. Gas chromatography-mass spectrometry (GC-MS) is a robust tool to analyse organic acids, sugars, and amino acids with a prior derivatisation (Desbrosses et al., 2005; Roessner et al., 2000). Liquid chromatography-mass spectrometry (LC-MS) can be used to separate and determine metabolites of different polarity, such as the broad class of secondary metabolites and lipids (Cheong et al., 2019; Jorge et al, 2015). We identified 64 primary metabolites, including sugars, organic acids and amino 
acids, 19 secondary metabolites, including phenolic compounds, betanin and saponins, and 240 lipids categorized in five groups including glycerolipids and phospholipids. We found some primary metabolites change in abundance in response to heat, cold and high-light stress, and some lipids change abundance in response to heat and salinity. We found that bladders contain betanin, which is presumably related to their pink colour, and saponins.

Although we found only few changes in the metabolic composition of bladders in response to abiotic stresses, metabolites related with heat, cold and high-light treatments were changed significantly.

\section{Material and Methods}

\section{Plant materials and growth conditions}

This experiment was conducted several times to enable collection of bladders in sufficient amounts for metabolomics analyses. Phenotypical traits were assessed for every experiment to ensure plants were stressed in a similar manner. Chenopodium quinoa (quinoa) accession QQ74 was grown in $10 \mathrm{~cm}$ diameter pots with Basissubtrat 2 (Stender, Schermbeck, Germany), in a Conviron growth chamber (day/night, 12/12 h, $22 / 18{ }^{\circ} \mathrm{C}, 50 \%$ humidity, incandescent lamps with photon flux density $300-350 \mu \mathrm{m} \mathrm{m}^{-2} \mathrm{~s}^{-1}$ ) or in a greenhouse at University Hohenheim, Germany. Plants were grown to the 11-leaf growth stage ( $\sim 26$ days) before they were subjected to treatments. Five seeds were sown per pot, and later thinned to one uniform plant per pot (runts and unusually strong plants were removed).

Pots with plants at the 11-leaf growth stage were placed in separate trays and subjected to each treatment for 6 days before harvesting. All treatment groups, other than water deficit, were watered to full field capacity on the first day of treatment. During the course of the treatment, all plants were watered when necessary. Plants were not treated with fungicides or insecticides. At harvest, plant height was measured from the soil surface to the top shoot meristem, shoot fresh mass (FM) and dry mass (DM) were determined.

\section{Heat, cold and high-light treatment}

Heat treatment was performed at day $/$ night $35 / 30^{\circ} \mathrm{C}$, cold treatment was performed at day $/$ night $10 / 5^{\circ} \mathrm{C}$, and for high-light treatments plants were exposed to a photon flux density of $\sim 700 \mu \mathrm{m} \mathrm{m}^{-2} \mathrm{~s}^{-1}$

\section{Water deficit treatment}

For water deficit treatment, the water holding capacity (WHC) of the soil from that experimental replicate was first determined, and plants were kept at a water holding capacity of 20-30\%, while the control plants were held around $60 \%$. A WHC of $60 \%$ was tested previously for control plants. The parameter of $20-30 \%$ WHC was chosen from preliminary testing, where plants were exposed to several water deficit stresses. At a WHC of 20-30\% a clear phenotype was visible, but plants did not die and could recover upon rewatering.

\section{Salt treatment}

For salt treatment, the plants were treated with a salt concentration of $300 \mathrm{mM} \mathrm{NaCl}$. Plants were soaked in the respective solutions for $4 \mathrm{~h}$. When the pots dried from fully soaked, at $100 \% \mathrm{WHC}$, to $60 \% \mathrm{WHC}$ (at which level pots were kept for the duration of the experiment), the apparent salt concentration in each pot increased to approximately $360 \mathrm{mM}$. While this application method does not allow the determination of accurate $\mathrm{NaCl}$ concentration in the pot, it enables comparisons between experiments. These parameters were chosen from a preliminary testing of four different concentrations, $300 \mathrm{mM}, 400 \mathrm{mM}, 500 \mathrm{mM}$ and $600 \mathrm{mM} \mathrm{NaCl}$, to ensure plants showed signs of stress but were not wilting and dying.

\section{Determining leaf ion content}

Measurements were done as described previously (Schmöckel et al., 2017). Briefly, at harvest, the ninth leaf of every plant was collected, the fresh and dry weight determined, then digested in $2 \mathrm{~mL}$ of $1 \%$ nitric acid for $4 \mathrm{~h}$ at $8^{\circ} \mathrm{C}$. The $\mathrm{Na}$ and $\mathrm{K}$ was determined using a Flame Photometer (Sherwood, Model 425). 


\section{WinFolia analyses}

During harvest, each leaf of one plant was placed in order on the scanner, the leaves were scanned, and the software used to determine leaf area.

\section{Statistical analysis}

Data was analysed using ANOVA, followed by Tukey HSD post hoc test.

\section{EBC collection and metabolite extraction}

EBCs were collected after six days of stress treatment. The EBCs were brushed from the abaxial and adaxial sides of the leaves, the petioles and the stem with a soft paintbrush. The EBCs from an entire plant were collected and snap frozen in liquid nitrogen. Samples were stored at $-80^{\circ} \mathrm{C}$ until further analysis.

\section{Analysis of primary metabolites}

All chemicals and solvents for metabolite measurements were purchased from Sigma-Aldrich (Australia) and were of analytical or mass spectrometry grades.

The snap-frozen bladders were freeze dried to give a dry mass per sample of 1-2 mg with an accurate mass being recorded. $250 \mu \mathrm{L}$ of $100 \%$ methanol (containing $0.005 \mathrm{mg} \mathrm{mL}{ }^{-113} \mathrm{C}_{6}$-Sorbitol $/{ }^{13} \mathrm{C}_{5}{ }^{15} \mathrm{~N}$-Valine internal standards) was added and the tissue homogenized in a cryomill at $-10^{\circ} \mathrm{C}$ (Precellys 24 , Bertin Technologies). The homogenate was sonicated for $2 \mathrm{~min}$, incubated for $15 \mathrm{~min}$ at $30^{\circ} \mathrm{C}$, centrifuged $(13,000 \mathrm{rpm}$ at room temperature) and the supernatant collected. The pellet was then washed $\left(250 \mu \mathrm{L}\right.$ of Milli-Q $\left.\mathrm{H}_{2} \mathrm{O}\right)$, vortexed, centrifuged (13,000 rpm at room temperature) and the supernatant collected. A $250 \mu \mathrm{L}$ aliquot of the combined supernatant was then dried under a vacuum and stored at $-20^{\circ} \mathrm{C}$.

For GC-MS analysis, samples were derivatised using a Gerstel MPS2 multipurpose sampler (GERSTEL GmbH \& Co. KG Mühlheim an der Ruhr, Germany). Briefly, $10 \mu \mathrm{L}$ of methoxyamine hydrochloride was added to each sample, shaken for $2 \mathrm{~h}$ at $37^{\circ} \mathrm{C}$ and then mixed with $20 \mu \mathrm{L} N, O$-Bis (Trimethylsilyl)trifluoroacetamide with Trimethylchlorosilane (BSTFA with $1 \%$ TMCS, Thermo Scientific), shaken for 30 min at $37^{\circ} \mathrm{C}$, with a $1 \mathrm{~h}$ wait before injection.

The analysis was performed on an Agilent 7890 gas chromatograph (Agilent Technologies Inc., Santa Rosa, CA, USA) coupled with an Agilent 5975C VL mass selective detector (Agilent Technologies Inc., Santa Rosa, CA, USA). Instrument control is performed with Agilent G1701A Revision E.02.01 ChemStation software (Agilent Technologies Inc., Santa Rosa, CA, USA). Separation was achieved with a Varian Factor 4 column (VF-5 ms; $30 \mathrm{~m} \times 0.25 \mathrm{~mm} \times 0.25 \mu \mathrm{m}+10 \mu \mathrm{m}$ Ezi-guard, Agilent Technologies Inc., Santa Rosa, CA, USA) with helium (Ultra High Purity) as carrier gas at flow rate $1 \mathrm{~mL} \mathrm{~min}^{-1}$ with retention time locking (RTL) applied (locked to mannitol at $21.5 \mathrm{~min}$ ). The initial oven temperature was set at $70^{\circ} \mathrm{C}(1 \mathrm{~min})$ with a temperature ramp of $7^{\circ} \mathrm{C} \mathrm{min}^{-1}$ to $325^{\circ} \mathrm{C}(3.5 \mathrm{~min}$ hold $)$. The mass spectrometer quadrupole temperature was set at $150^{\circ} \mathrm{C}$, the source at $250^{\circ} \mathrm{C}$ and the transfer line was held at $280^{\circ} \mathrm{C}$. Ionization energy was $70 \mathrm{eV}$ and the MS data was recorded in full scan mode $(\mathrm{m} / z$ 50-600).

\section{Analysis of lipid composition}

All chemicals and solvents for metabolite measurements were purchased from Sigma-Aldrich (Australia) and were of analytical or mass spectrometry grades.

The snap-frozen bladders were weighed, supplemented with $200 \mu \mathrm{L}$ MilliQ water and vortexed vigorously for 1 min. $250 \mu \mathrm{L}$ of $100 \%$ methanol, containing $0.01 \%$ butylated hydroxytoluene (BHT) and $10 \mu \mathrm{M}$ d7cholesterol (internal standard), were added. Samples were sonicated for $5 \mathrm{~min}$ in a water bath at room temperature. Then $500 \mu \mathrm{L}$ of chloroform was added, vortexed vigorously for 1 min and incubated for 30 minutes at $30^{\circ} \mathrm{C}$. Samples were centrifuged for $15 \mathrm{~min}$ at $15,000 \mathrm{rpm}$ at room temperature. The supernatant was transferred into a fresh tube. $1000 \mu \mathrm{L}$ of chloroform: methanol $(2: 1)(\mathrm{v} / \mathrm{v})$ were added to the remaining pellet ( $2^{\text {nd }}$ extraction), vortexed for $1 \mathrm{~min}$, centrifuged 15 minutes at 15,000 rpm at room temperature and 
the supernatant combined with the previously collected supernatant. Combined extract was dried under vacuum und resuspended in $200 \mu \mathrm{L}$ of $10 \mathrm{mM}$ ammonium formate in butanol:methanol (50:50, v/v).

The targeted lipid analysis was performed by LC-QqQ-MS. Samples $(5 \mu \mathrm{L})$ were injected into a $50 \mathrm{~mm} \times$ $2.1 \mathrm{~mm} \times 2.7 \mu \mathrm{m}$ Ascentis Express RP Amide column (Supelco, Sigma, St Louis, USA) at the temperature of $35^{\circ} \mathrm{C}$ using an Agilent LC 1200 (Mulgrave, Australia). Followed by an elution at $0.2 \mathrm{~mL} \mathrm{~min}{ }^{-1}$ over a 5 min gradient of $50: 20: 30 \mathrm{v} / \mathrm{v} / \mathrm{v}$ water:methanol:tetrahydrofuran to $5: 20: 75 \mathrm{v} / \mathrm{v} / \mathrm{v}$ water:methanol:tetrahydrofuran; the latter buffer hold for 3 min. Electrospray Ionization Mass Spectrometry (ESI-MS) with an Agilent Triple Quad 6490 (Mulgrave, Australia) was used to detect the lipids. Mass spectra of lipid species were detected using a precursor ion scanning with the range of 100-1000 $\mathrm{m} / \mathrm{z}$, in both positive and negative ion mood. Phosphatidylcholines (PC, precursors of $m / z$ 184.1), sphingomyelins (SM, $m / z$ 184.1), phosphatidylglycerols (PG, $m / z$ 189), and ceramides (CER, $m / z$ 264.6) were detected using positive ion mode and phosphatidylinositols (PI, $m / z$ 241) were identified using negative ion mode. To detect the phosphatidylethanolamines (PE, in positive ion mode, neutral loss of $m / z$ 141) and phosphatidylserines (PS, negative ion mode, $m / z$ 87) neutral loss scanning was applied. In addition, the triacylglycerol (TAG) and diacylglycerol (DAG) species were detected using the neutral loss of fatty acyl moiety. MRM with a $20 \mathrm{~ms}$ dwell time for the simultaneous measurement of approximately 20-50 compounds, the peak width of 30-45 sec, the minimum of 12-16 collected data points across the peaks was used for the quantification of the detected lipid species. The capillary voltage was set at $4000 \mathrm{~V}$, and the collision and fragmentor voltages were set at 15-60 V and 140-380 V, respectively.

The untargeted lipid analysis was facilitated by LC-QqTOF. An Agilent 1290 HPLC system (Santa Clara, CA, USA) coupled to a SCIEX TripleTOF 6600 mass spectrometer (Framingham, Massachusetts, USA) were employed for lipid analysis and identification. Samples $(8 \mu \mathrm{L})$ were injected using an Agilent Poroshell EC$\mathrm{C} 18(100 \mathrm{~mm} \times 2.1 \mathrm{~mm}, 2.7 \mu \mathrm{m}, \mathrm{Col} \mathrm{A})$ column, at the temperature of $50^{\circ} \mathrm{C}$, and a flow rate of $0.4 \mathrm{~mL} \mathrm{~min}^{-1}$ followed by an elution at $0.4 \mathrm{~mL} \mathrm{~min}{ }^{-1}$ over a linear gradient of $3: 7 \mathrm{v} / \mathrm{v}$ methanol:20 $\mathrm{mM}$ ammonium acetate and 6:3:1 v/v/v 2-propanol:methanol:20 $\mathrm{mM}$ ammonium acetate. The starting conditions of the gradient pump were set at $35 \%$ for $\mathrm{A}$ and $65 \%$ for B, over $2 \mathrm{~min}$. The linear gradient for B was increased to $100 \%$ over 8 min, followed by $100 \%$ for B over 4 min, and then back to the same condition (35\% for A and $65 \%$ for $\mathrm{B}$ ) over $6 \mathrm{~min}$. For each lipid class the collision energy (CE) was adjusted as follows; for phosphatidylcholine $(\mathrm{PC})$

and phosphatidylethanolamine (PE) families the $\mathrm{CE}$ was set at $+38 \mathrm{~V}$; for steryl esters (SE), diacylglycerol (DG), acylated steryl glycoside (ASG) and steryl glycoside (SG) families, at $+30 \mathrm{~V}$; for ceramide (Cer) and glucosyl ceramide (GlcCer) families, at $+50 \mathrm{~V}$; for triacylglycerol (TAG) and steryl esters (SE) families, at +40 V. For digalactosyl diacylglycerol (DGDG), lysodigalactosyl diacylglycerol (LDGDG), lysomonogalactosyl diacylglycerol (LMGDG), lysophosphatidylcholine (LPC), lysophosphatidylethanolamine (LPE), lysophosphatidylglycerol (LPG), lysophosphatidylinositide (LPI), lysosulfoquinovosyl diacylglycerol (LSQDG), monogalactosyl diacylglycerol (MGDG), phosphatidic acid (PA), phosphatidylglycerol (PG), phosphatidylinositide (PI), phosphatidylserine (PS), and sulfoquinovosyl diacylglycerol (SQDG) families the CE was set at $-40 \mathrm{~V}$. The source temperature was set at $450 \mathrm{degC}$. The atmospheric pressure of the Curtain Gas, Gas 1, and Gas 2 were set at 45 psi. Declustering potential (DP) voltage was set at $-200 \mathrm{~V}$ in negative ion mode and $+100 \mathrm{~V}$ in positive ion mode. The voltage of ion spray voltage floating (ISVF) was set to $+5500 \mathrm{~V}$ in positive ion mode and $-4500 \mathrm{~V}$ in negative ion mode.

\section{Analysis of secondary metabolites}

All chemicals and solvents for metabolite measurements were purchased from Sigma-Aldrich (Germany) and were of analytical or mass spectrometry grades.

The snap-frozen bladders were ground using mortar and pestle and weighed to 0.5-2 g. $1 \mathrm{~mL}$ of methanol:water:chloroform $(1: 1: 1 \mathrm{v} / \mathrm{v})$ solvent was added, vortexed for $15 \mathrm{~min}$, sonicated for $15 \mathrm{~min}$ and centrifuged for $15 \mathrm{~min}$ (13,000 rpm at room temperature). The upper phase was extracted, concentrated using nitrogen with XcelVap Concentrator (Biotage, Uppsala, Sweden) and resolved in $100 \mu \mathrm{L}$ methanol. 
The samples were stored at $-20^{\circ} \mathrm{C}$ until analysis.

HPLC-MS/MS analysis was performed on a UHPLC-Agilent 1290 Infinity LC System (Agilent Technologies Inc., Santa Rosa, CA, USA). Separation was achieved on a Zorbax Eclipse Plus C18 column (50 x $2.1 \mathrm{~mm}$, $1.8 \mu \mathrm{m}, 100 \AA$ A ; Agilent Technologies Inc., Santa Rosa, CA, US). Elution proceeded by means of a gradient with $0.2 \mathrm{~mL} \mathrm{~min}^{-1}$ flow rate, using water with $0.2 \%$ formic acid as solvent $\mathrm{A}$ and acetonitrile with $0.2 \%$ formic acid as solvent B. The elution profile was: 0-35 min, 0-10 \% B; 36-43 min, 10-15\% B; 44-70 min, 15-65 \% B; 71-80 $\min , 65-100 \% \mathrm{~B}$; 81-85 min, $100 \% \mathrm{~B}$; 86-90 min, 100-0 \% B. The temperatures of the LC column and autosampler were maintained at $40^{\circ} \mathrm{C}$ and $4^{\circ} \mathrm{C}$, respectively. The injection volume of all samples was $12 \mu \mathrm{L}$. The UHPLC was coupled to a Q Exactive Hybrid-Quadrupole-Orbitrapmass spectrometry operated with Xcalibur 4.0 (ThermoFisher, Waltham, MA, USA), equipped with an electrospray ion source (ESI). The mass spectra were acquired in positive ion mode with a spray voltage at $4200 \mathrm{~V}$. The sheath gas had $60^{\circ} \mathrm{C}$, aux gas $20^{\circ} \mathrm{C}$, and capillary temperature was $360^{\circ} \mathrm{C}$. The S-lens RF level was set at 50 and the heater temperature at $380^{\circ} \mathrm{C}$. The scan range was used from 100 to $1,500 \mathrm{~m} / z$ at a resolution of 70,000 . Datadependent MS/MS spectra in a mass range of 200-2,000 $\mathrm{m} / z$ were generated for the five most abundant precursor ions with a resolution of 17,500 and a stepped collision energy of 10,60, and $110 \mathrm{eV}$.

\section{Raw data and statistical analysis of metabolites}

Primary metabolites and lipids

Peak finding software AMDIS (https://chemdata.nist.gov), Agilent MassHunter Qualitative Analysis and Agilent MassHunter Quantitative Analysis (Agilent Technologies Inc., Santa Clara, CA, USA) were used for analysis of the raw data. The data were normalised to the internal standard (ISTD) response and sample weight. For primary metabolite identification, the NIST Standard Reference Database 78 (version 5.8, https://dx.doi.org/10.18434/T4W30F) and an in-house mass spectral database were used, while the MSDIAL lipid database was used for lipid identification (Tsugawa et al., 2020). The online tool MetaboAnalyst (Metaboanalyst.ca, 2020) was then utilised for statistical analysis of the normalised raw data and generation of PCA plots, $t$-Test and One-Way Analysis of Variance (ANOVA) was applied to the data. The ANOVA was used with a false discovery rate (FDR)-adjusted $p$ value of 0.05 and using the Benjamin Hochberg method (1995) to determine the metabolites and lipids that changed significantly in comparison to the control. The comparisons between treatment and control for metabolites and lipids are presented as $\log _{2}$-transformed fold change values. The $\log _{2}$-fold changes of primary metabolites and lipids were calculated and plotted using stats $\mathrm{R}$ package and using the ggplot2 package.

Secondary metabolites

Compound Discoverer 3.1 (ThermoFisher Scientific, Waltham, MA, USA) was used for feature finding, further compound identification, normalising the data in response to quality control samples (QC) and identification the metabolites by the Core Facility, Metabolomics Unit at the University of Hohenheim. Based on the isotopic and fragmentation pattern features where sorted, e.g. resulting from not correct assigned adduct signals. The resulting data set was used for further investigation. The QC-normalised data was further normalised by the sample weight. The online tool MetaboAnalyst (Metaboanalyst.ca, 2020) was then utilised for statistical analysis of the normalised raw data and generation of PCA plots, T-Test and One-Way Analysis of Variance (ANOVA) was applied to the data. The ANOVA was used with a false discovery rate (FDR)-adjusted $p$ value of 0.05 and using the Benjamin Hochberg method (1995) to determine the metabolites that changed significantly in comparison to the control. The comparisons between treatment and control for metabolites are presented as $\log _{2}$-transformed of fold change values. The $\log _{2}$-fold changes of primary metabolites and lipids were calculated and plotted using stats R package and using the ggplot2 package.

\section{Results}

The metabolic and lipid profile of quinoa bladders 
To characterize quinoa's EBCs, a combination of metabolic and lipid profiling was used. In total, 64 primary metabolites (13 sugars, 6 sugar alcohols, 4 sugar acids, 13 organic acids, 8 amino acids, 13 fatty acids and fatty alcohols and 7 uncategorised) were identified using GC-Q-MS, including oxalic acid, octacosanol, octadecanoic acid, hexacosanol, pyroglutamic acid and sucrose (Supplementary Table S1 ). Some of these metabolites have been reported before in seeds and leaves of quinoa (Kiani-Pouya et al., 2017; Pereira et al., 2019). We identified 240 lipids using targeted LC-MS, that can be categorised in five groups: Sphingolipids (9), Glycerolipids (55), Glycosyldiacylglycerols (20), Phospholipids (146) and Sterols (11) (Supplementary Table S2 ). In addition, over 4000 unidentified mass features were found and relative-quantified using untargeted LC-MS. Highly abundant in the EBCs are three diglycerides (DG), one triglyceride (TG), four phosphatidylcholines (PC) and an unidentified lipid (m/z 510.0644 at RT 19.91).

Secondary metabolites were relative-quantified using untargeted LC-MS and revealed 1200 mass features. The features were scanned for known secondary metabolites in quinoa, according to their isotopic and fragmentation pattern. We identified 19 compounds: 10 flavonols, 2 betacyanins, 1 sterol, 3 saponins and 3 hydrocinnamic acids. The compounds are presented with a tentative identification, based on mass, mass formula, MS/MS fragmentation and literature (Table 1). The flavonols were the most represented secondary metabolites, in particular glycosylated derivatives of quercetin, isorhamnetin, rhamnetin and kaempferol. Quercetin and kaempferol are common flavonols in quinoa and have been reported before in seed and leaf samples. The presence of either rhamnetin and isorhamnetin seems to depend on the quinoa accession (El-Sadek et al., 2017; Gómez-Caravaca et al., 2012; Paśko et al., 2008; Stikić et al., 2020). The two betacyanins betanin and amaranthin presumably provide the visible rose/pink colour in the EBCs. In quinoa seeds betacyanins are responsible for the colouring (Tang, Li, Chen, et al., 2015). Betanin was identified using a standard and amaranthin identified based on its MS2 spectra, as well as their longer absorption wavelength (536-538 nm). Hydrocinnamic derivatives, ferulic, sinapinic and coumaric acid were identified in their glycosylated form as ammonia adducts. These polyphenols are common in their non-derivatised form in quinoa seeds (Gómez-Caravaca et al., 2012; Tang, Li, Chen, et al., 2015). Saponins, mainly stored in the seed hulls of quinoa, were also identified in the EBCs (Jarvis et al., 2017; Madl et al., 2006). However, the aglycone structure could not be exactly identified. A phytoecdysteroid was found in the bladders, which has been reported in seeds and the whole plant of quinoa before (El-Sadek et al., 2017; Graf et al., 2014; N. Zhu et al., 2001).

\section{The metabolic and lipid profile of quinoa bladders changed in response to abiotic stresses}

To investigate the role of EBCs in quinoa, we analysed the metabolic and lipid composition in response to various abiotic stimuli, including heat, cold, high-light, water deficit and soil salinity. To ensure plants were affected by treatments, physiological parameters were determined. The experiment was repeated several times to ensure sufficient amounts of bladders could be obtained. Each time several physiological parameters were taken to confirm plants were responding on a physiological level. Plant height, fresh biomass and total leaf area were significantly reduced for cold, high-light and water deficit treatments (Fig. 2 A-C ). Quinoa is considered a salt tolerant plant; therefore, it is not expected to alter biomass significantly during salt imposition. One important trait to investigate is the Na concentration, which increased significantly in the leaves of plants treated with $300 \mathrm{mM} \mathrm{NaCl}$ (Fig. 2 D ). Plant height was also significantly reduced in response to salt imposition, while plant biomass and total leaf area were only slightly reduced compared with control conditions.

The heat treatment did not significantly affect any of the measured traits, although a trend was apparent. This is consistent with other studies (Eustis et al., 2020; Hinojosa et al., 2019). However, it was clearly visible that leaves were positioned upright during heat treatment (Fig. 2 E ).

\section{Heat, cold and high-light stress elicit changes in primary metabolites}

Principal component analysis (PCA) presented an unbiased assessment of the data variance structure. The first principal component (PC1) demonstrates the greatest variance $(44.3 \%)$ across the data and separates the data across the samples based on the treatment (Fig. 3 A ). The second principal component divides 
the components based on sample replicates and accounts for $14.4 \%$ of the variance. Changes in primary metabolites were seen predominantly in EBCs of heat, cold and high-light treated plants (Fig. 3 A ). Changes in the 64 primary metabolites were observed in heat, cold and high-light-treated plants, mainly in sugars, sugar alcohols and sugar acids. Heat-treated plants showed changes in $70 \%$ of the measured metabolites (Fig. 3 B ). The PCA Biplot revealed that the sugars glucose and fructose contributed most to the response to cold treatment, while saccharic/glucaric acid and melibiose contributed to the response to heat treatment (Supplementary Fig. S1 ).

Analysing the GC-MS data of the stress treatments showed a significant increase in sugars, sugar acids and sugar alcohols in the EBCs of cold and high-light treated quinoa plants (Fig. 3 C $)$. Fructose $(+1.6$ fold), glucose $(+3.7$ fold) and galactonic acid $(+1.2$ fold) increased during cold treatment (Fig. $\mathbf{3} \mathbf{C})$, while ribonic acid ( +1.6 fold) and ribitol ( $+1,1$ fold) increased significantly during high-light treatment.

In response to heat treatment, we detected a significant increase in abundance for 12 primary metabolites and a significant decrease in abundance for 9 primary metabolites (Fig. $3 \mathbf{C}$ ). A significant increase was seen for the amine tyramine $(+1.1$-fold $)$, the three organic acids malic acid $(+1.9$-fold $), 1,4$-lactone-threonic acid $(-0.6$ fold $)$ and ribonic acid $(+2.1$-fold $)$; the two sugars rhamnose $(+0.5$ fold $)$ and melibiose $(+0.8$ fold $)$, the four sugar alcohols erythritol ( +2.4 fold), arabitol $(+1.3$ fold $)$, myo-inositol $(+1$ fold $)$ and ribitol $(+0.7$ fold $)$; and the three sugar acids galactonic acid $(+0.9$ fold $)$, sacharric/glucaric $(+1.4$-fold $)$ and threonic acid $(+0.4$ fold). A significant decrease was seen in the four fatty acids docosanoic acid (-2 fold), eicosanoic acid (-1.7 fold), heptadecanoic acid (-1.6 fold) and pentadecanoic acid (-1.3 fold), the organic acid lactic acid (-1.3 fold); the two sugars fructose (-0.9 fold) and sucrose (-2 fold), and the sugar alcohol derivative digalactosylglycerol (-1 fold).

\section{Cold and salt stress elicit few changes in lipids}

Lipid profile changes were analysed by LC-MS with a targeted and an untargeted measurement approach. The PCA Scoreplots of the targeted lipid analysis (Fig. 4 A, Supplementary Table S2 ) and the untargeted lipid analysis (Fig. 4 B, Supplementary Table S3 ) in the EBCs show little distinction between the treatment groups. The other treatments showed a disperse variance within their respected groups and the observation is similar for targeted and untargeted lipids.

Regarding the targeted lipids, only three glycerolipid (one TG, two GlcCer), two phospholipids of the PC class, and three lipids of the sphingolipids (Cer) were significantly increased in EBCs of heat and salt-treated plants compared to the controls (Fig. $4 \mathbf{C}$ ).

In cold treated bladders only one unidentified lipid increased significantly compared to the control (840.566_1.11 (+0.86 fold)). The same lipid decreased in the NaCl-treated plants (Supplementary Table S3 ). In heat-treated EBCs significant increases were observed in six lipids (Cer(18:1;3/22:0;1) (+1.5 fold), GlcCer(18:1;3/22:0;1) (+2 fold), GlcCer(18:1;3/24:0;1) (+2 fold), PC 31:0 (+2.5 fold), PC 31:1 (+1.7 fold), TG 50:0 (+0.5 fold)) and 11 unidentified lipids (Supplementary Table S2 ). The EBCs from plants treated with salinity displayed a significant increase in seven unidentified lipids with 1078.8384_16.28 (+1.7 fold) increasing the most. No changes were observed in the EBCs of high-light stressed plants. The most changes in the lipid composition were observed in the water deficit-treated quinoa plants with 46 unidentified lipids (Supplementary Table S3 ).

\section{Secondary metabolites change little under abiotic stresses}

Secondary metabolites in EBCs of stressed quinoa plants were measured by LC-MS. The untargeted LC-MS approach revealed 1200 mass features. These features were further analysed, based on MS/MS signal and signal strength to 600 mass features. Due to a high variance in sample weight between the stress treatments, the data was not sufficient for quantification. Therefore, we could only observe trends in this dataset. Hence, the PCA showed no distinct differences between the treatment groups (Fig. 5 A, Supplementary Table S4).

The identified peaks of the secondary metabolite analysis (Table $\mathbf{1}$ ) were not significantly regulated upon 
stress treatment in the EBCs of quinoa. However, some of the compound groups display a trend in their response to abiotic stress treatment. The three saponins displayed an interesting pattern. Compared to the control samples, the saponins increased in water deficit and salt-treatment, and decreased in heat, cold, and high-light treated plants (Fig. 5 B ). Similar observations have been made in quinoa seed samples under salt irrigation experiments. There, the saponin content was higher in saline water irrigated plants compared to the water irrigated plants. In contrast, plants grown under an irrigation deficit showed a decrease of saponins (Gómez-Caravaca et al., 2012; Pulvento et al., 2012).

In contrast to saponins, betacyanins are increased in bladders treated with heat, cold and high-light stress and decreased in water deficit and salt stress treatment. Betacyanins have antioxidant activities and increase in abundance when exposed to salt and high-light (Oh et al., 2015; Vogt et al., 1999; Wybraniec et al., 2011).

The flavonoids showed similar trends under the different stress-treatments, with a few exceptions. In bladders from high-light stressed plants, the three isorhamnetins show a higher increase than the other flavonoids. In heat and high-light treated bladders the flavonoids increased to varying degree, additionally kaempferol coumaroyl-glucoside decreased compared to the controls. The cold-treated bladders showed an increase of all flavonoids compared to the control. The stress-induced pattern of the flavonoids is consistent with their role as reactive oxygen species (ROS) scavengers and their abundance increases in response to several abiotic stresses (Agati et al., 2012; Agati \& Tatt, 2010).

\section{Discussion}

We used multiple analytical approaches to characterize quinoa's EBCs. We detected more than 5000 metabolites consisting of 340 known and over 4000 unidentified molecular features. It has been suggested that quinoa's EBCs play an important role in salinity tolerance mechanisms (Böhm et al., 2018; Kiani-Pouya et al., 2017). To gain greater insight into the biochemical profile underlying biological roles of the EBCs, we studied the effect of different abiotic stress treatments on the EBC metabolites. Our data suggest that the EBCs might have multiple roles protecting quinoa from abiotic stressors.

In summary, primary metabolite levels in EBCs revealed significant metabolic responses upon heat, cold and high-light stress treatment (Fig. 3 A ), while alterations in secondary metabolites were not significant in any (Fig. 5 B ). The lipid composition in the EBCs varied in all treatments, with the most substantial changes during heat and drought stress (Fig. $4 \mathrm{C}$ ).

The detected primary metabolites including oxalic acid and several compounds known to be involved in defence against pest and animals (Franceschi \& Nakata, 2005). Plants were not treated with fungicides/pesticides and were cultivated in closed growth cabinets, reducing the likelihood that these compounds came from elsewhere. Oxalic acid is also highly concentrated in quinoa seeds, where it poses a palatability problem (Pereira et al., 2019). Octacosanol and hexacosanol are aliphatic primary alcohols, which are constituents of plant epicuticular wax (Jenks et al., 1996). This wax layer preserves the water balance and minimizes mechanical damage in epidermal cells (Shepherd \& Griffiths, 2006). In EBCs these compounds might function in a similar way, stabilizing the EBC cell wall and therefore protecting the surface of the leaf as a secondary epidermis. Pyroglutamic acid is a potential precursor of glutamate, which is essential for the first step in the de novo biosynthesis of the antioxidant glutathione (Forman et al., 2009; Kumar \& Bachhawat, 2012). Previous studies have shown that purified pyroglutamic acid exhibits antibacterial properties against Bacillus and Enterobacter strains, as well as antifungal activity against phytopathogens (Huttunen et al., 1995; F. Zhu et al., 2018).

Primary metabolites in EBCs changed mainly in sugar concentrations in response to heat, cold and highlight stress (Fig. 3 C ). Sugars act as osmolytes to stabilize the turgor pressure and the cell membrane, as well as preventing protein degradation (Arbona et al., 2013). Fructose and glucose are the main sugars changing in the EBCs of cold treated plants, probably acting as osmoprotectants in the cells. This increase is probably facilitated by the detected sugar transporters, which were recently identified using transcriptome analyses by Böhm et al. (2018). Besides these typical sugars, no other known osmolytes are elevated in 
the EBCs of any stress treated plants, such as proline, betanin and other soluble sugars. Transgenic plants with increased levels of raffinose and galactinol showed an increased tolerance towards salinity and low temperature stress, presumably by scavenging hydroxyl radicals to protect from oxidative stress (Nishizawa et al., 2008). Neither galactinol, nor raffinose increased significantly in quinoas EBCs. The same was observed for trehalose, a disaccharide linked to increase under drought, salt and cold tolerance, as shown in transgenic rice and tobacco plants (Shima et al., 2007; Zhang et al., 2005). Typical protective osmolytes are not elevated in the EBCs of quinoa under any abiotic stressor, suggesting that the EBCs are not cells that are protected.

The cytosolic accumulation of osmotically active compounds might increase the cellular osmotic potential to provide a balance between the cytoplasm and the vacuolar lumen, which in $M$. crystallinum, can accumulate up to $1 \mathrm{M} \mathrm{Na}^{+}$(Adams et al., 1998). Transcriptomic data of the salt treated EBCs from $M$. crystallinumsuggests metabolic pathways are induced which lead to synthesis, accumulation, transport and conversion of compatible solutes to balance the osmotic potential (Oh et al., 2015). We did not see a large amount of $\mathrm{Na}^{+}$accumulate in EBCs (Supplementary Fig. 2 ). This corroborates a recent study, that found that the small amount of ions accumulated in the EBCs and the general small weight of the EBCs $(1.3 \%)$ represents only a very small fraction of the total $\mathrm{Na}^{+}$taken up by the plant and therefore presumably plays only a minor role in $\mathrm{Na}^{+}$storage (Roman et al., 2020). The accumulated sugars in quinoas EBC might counterbalance the $\mathrm{Na}^{+}$; however, even under salt stress conditions no particular increase of sugars was measured to facilitate this. This leaves the role of the osmolytes unanswered.

Another hypothesis of the elevated osmotically active non-toxic organic compounds could be to facilitate storage of toxic protective compounds. Natural deep eutectic solvents (NADES) are proposed to be the third intracellular solvent phase (Choi et al., 2011). This group is composed of natural compounds including main plant cell constituents such as sugars, amino acids, choline and organic acids. In the right stoichiometric proportions these crystalline structures become liquid; the most common example is honey with its 1:1:1 molar ratio of glucose:fructose:sucrose. Due to the formation of intramolecular hydrogen bonds the high melting point is depressed and causes the solids to liquefy, even at room temperature. This characteristic makes NADES excellent solvents for insoluble phytochemicals such as anthocyanins and flavonoids (Choi et al., 2011; Dai et al., 2013). The properties of NADES could serve to protect phytochemicals by retaining water during dehydration caused by abiotic stresses like drought and heat, as NADES have almost no vapour pressure (Knudsen et al., 2018). Many studies report correlations of drought tolerance with induction of sugars (di- and oligosaccharides) and amino acids (proline, glycine) (Ancillotti et al., 2015; Guy et al., 2008; Hoekstra et al., 2001; Iordachescu \& Imai, 2008; Szabados \& Savouré, 2010). Many of these compounds have been shown to act as NADES, suggesting that plants might replace water with NADES to maintain life under drought conditions (Choi et al., 2011).

Typical NADES are formed like sugar:organic-acid; sugar:sugar, amino-acid: sugar, and amino-acid:organicacid. In the EBCs of cold treated quinoa plants glucose, fructose and galactonic acids are increased, and these osmoprotectants might be able to form NADES. In heat treated quinoa EBCs, the organic acid malic acid and sugars like rhamnose and melibiose are increased, and this combination may form NADES as well. Under these abiotic stress conditions, NADES might be formed to protect valuable metabolites like flavonoids.

This is the first study to report on secondary metabolites of quinoa's EBCs. We identified glycosylated flavonoids, betacyanins, sterols, saponins and hydrocinnamic acids. These are known to be involved in adaptations to environmental changes and plant defence (Agati et al., 2012; Gómez-Caravaca et al., 2012; Oh et al., 2015; Vogt et al., 1999). An increase in reactive oxygen species (ROS) can result from many abiotic stressors (Miller et al., 2010). Flavonoids are known ROS scavengers, acting as antioxidants in stressed plants (Agati \& Tatt, 2010; Ferdinando Di et al., 2012). The identified glucosylated flavonoids in this study were not significantly increased under any abiotic stressor. However, most of them were elevated during cold stress-treatment compared to the control bladders. In cold-tolerantArabidopsis thaliana accessions the up-regulation of flavonoids was positively correlated (Hannah et al., 2006).

The detected betacyanins are known in quinoa and found in diverse parts of the plant (Repo-Carrasco et al., 2003; Tang et al., 2015). Betacyanins are described in M. crystallinum being strongly correlated with light 
intensity (Ibdah et al., 2002; Vogt et al., 1999), as betacyanins have a strong antioxidant capacity (Taira et al., 2015). We detected increased levels of betanin and amaranthin in EBCs of heat, cold and high-light treated plants (Fig. 5 B ). However, the values are not significant and prevent conclusions of high-light and betacyanin induction/correlation in quinoa.

Saponins in quinoa are mainly known in the hull of the seeds and to some extent in the leaves (Jarvis et al., 2017; Madl et al., 2006). During salt irrigation experiments, elevated saponin levels in the seeds were measured compared to the water irrigated control plants (Gómez-Caravaca et al., 2012; Pulvento et al., 2012). We observed a similar trend in salt stressed plants, where the saponin levels were slightly elevated in the EBCs of salt stressed plants. In contrast, saponin content has been reported to decrease in seeds under drought conditions (Gómez-Caravaca et al., 2012; Pulvento et al., 2012), while we observed a moderate elevation of the saponin levels in the EBCs. Whether saponins play any kind of role in conveying resistance to abiotic stresses remains unclear.

Plant cellular membrane lipids undergo many changes when exposed to abiotic stresses. The membrane fluidity changes with abiotic stressors, as the ratio of phospholipids changes (Barkla, Rhodes, et al., 2018; Falcone et al., 2004; Larkindale \& Huang, 2004). In our study, four phospholipids (PC) and four glycerolipids (DG, TG) are the most abundant plasma membrane lipids. PCs and PAs are phospholipids known to be involved in membrane synthesis. EBCs of salt stressed $M$. crystallinum showed increased levels in multiple phospholipid classes, suggesting an adaptive advantage of the plant (Barkla et al 2018). While in EBCs of $M$. crystallinum 34 lipid molecular species changed upon salt stress, none of these lipids change in quinoas EBCs. In recent studies, the neutral glycerolipids triacylglycerols (TG) has been linked to heat stress, oxidative stress and salt stress (Barkla, Garibay-Hernández, et al., 2018; Fan et al., 2017; Higashi et al., 2015). In $M$. crystallinum neutral glycerolipids from the TG species decreased upon salt treatment, while in quinoa only one statistically responsive TG species increased upon salt and heat treatment. The EBCs of M. crystallinum enlarge substantially upon salt stress to accumulate the ions in their (Oh et al., 2015), therefore a remodelling of the cell wall might be necessary to accommodate this swelling (Barkla et al., 2018). A substantial swelling of quinoas EBCs has not been observed (Supplementary Fig. 2 ). A recent study suggests that quinoa plants without EBCs are severely damaged by UV-B irradiation, but did not display a $\mathrm{NaCl}$ or drought sensitivity (Imamura et al., 2020), which is in agreement with our findings.

In conclusion, we detected in the EBCs some metabolites that may have defensive effects, like saponins and oxalic acid and we detected betanin, which may be causing the pink colour of EBCs. However, in response to abiotic stress treatments, we observed only few changes of primary metabolites and lipids. The data of this study does not indicate a clear role of the EBCs in quinoa related to certain abiotic stress tolerance mechanisms. The results neither support the notion that EBCs comprise an external storage for toxic ions, nor do they appear metabolically highly active, as seen in other plants like M. crystallinum . Future studies may investigate if EBCs play a role in protecting the epidermis and the apical meristem from UV-B or mechanical damage or if they function as storage of metabolites, given the accumulation of sugars and organic acids.

\section{Acknowledgements}

HK was supported by King Abdullah University of Science and Technology (VSRP funding). SMS received funding from the Ministry for Science, Research and Art of Baden-Wuerttemberg, Germany (Az: 75533-3020/1). Lipid and primary metabolite analyses were performed at Metabolomics Australia at University of Melbourne, which is a National Collaborative Research Infrastructure Strategy initiative under Bioplatforms Australia Pty Ltd (http://www.bioplatforms.com/). We thank Noha O. Saber (KAUST, Saudi Arabia) for technical assistance, Alexa Wangler und Pascal Wendel (BSc, UHOH, Germany) for help with bladder collections. All authors declare no conflict of interest.

\section{Author contributions}

SO, UR, DEJ, MT and SMS designed the research. HK, SO performed the experiments and acquired the experimental data. TR, HM, KHK, VL, SHAN, IK performed metabolomics analyses and respective data 
analysis. SO, HK, NMA, DEJ and SMS integrated data analyses and contributed figures. All authors contributed to the interpretation of the data. MT, UR and SMS acquired funding. SO, HK, and SMS drafted the manuscript. All authors reviewed and approved the final manuscript.

\section{References}

Adam, K. P., \& Zapp, J. (1998). Biosynthesis of the isoprene units of chamomile sesquiterpenes. Phytochemistry , 48 (6), 953-959. https://doi.org/10.1016/S0031-9422(97)00992-8

Adams, P., Nelson, D. E., Yamada, S., Wendy, C., Jensen, R. G., Bohnert, H. J., \& Griffiths, H. (1998). Growth and development ofMesembryanthemum crystallinum (Aizoaceae). New Phytologist, 138 (97), 171190.

Adolf, V. I., Jacobsen, S. E., \& Shabala, S. (2013). Salt tolerance mechanisms in quinoa (Chenopodium quinoa Willd.).Environmental and Experimental Botany, 92 , 43-54. https://doi.org/10.1016/j.envexpbot.2012.07.004

Agarie, S., Shimoda, T., Shimizu, Y., Baumann, K., Sunagawa, H., Kondo, A., Ueno, O., Nakahara, T., Nose, A., \& Cushman, J. C. (2007). Salt tolerance, salt accumulation, and ionic homeostasis in an epidermal bladder-cell-less mutant of the common ice plant Mesembryanthemum crystallinum. Journal of Experimental Botany , 58 (8), 1957-1967. https://doi.org/10.1093/jxb/erm057

Agati, G., Azzarello, E., Pollastri, S., \& Tattini, M. (2012). Flavonoids as antioxidants in plants: Location and functional significance. Plant Science , 196 , 67-76. https://doi.org/10.1016/j.plantsci.2012.07.014

Agati, G., \& Tatt. (2010). Multiple functional roles of flavonoids in photoprotection. New Phytologist , 186 , 786-793.

Ancillotti, C., Bogani, P., Biricolti, S., Calistri, E., Checchini, L., Ciofi, L., Gonnelli, C., \& Del Bubba, M. (2015). Changes in polyphenol and sugar concentrations in wild type and genetically modifiedNicotiana langsdorffi Weinmann in response to water and heat stress. Plant Physiology and Biochemistry , 97 , 52-61. https://doi.org/10.1016/j.plaphy.2015.09.012

Arbona, V., Manzi, M., de Ollas, C., \& Gómez-Cadenas, A. (2013). Metabolomics as a tool to investigate abiotic stress tolerance in plants. International Journal of Molecular Sciences ,14 (3), 4885-4911. https://doi.org/10.3390/ijms14034885

Barkla, B. J., Garibay-Hernández, A., Melzer, M., Rupasinghe, T. W. T., \& Roessner, U. (2018). Single cell-type analysis of cellular lipid remodelling in response to salinity in the epidermal bladder cells of the model halophyte Mesembryanthemum crystallinum . Plant Cell and Environment , 41 (10), 2390-2403. https://doi.org/10.1111/pce.13352

Barkla, B. J., Rhodes, T., Tran, K. N. T., Wijesinghege, C., Larkin, J. C., \& Dassanayake, M. (2018). Making epidermal bladder cells bigger: Developmental-and salinity-induced endopolyploidy in a model halophyte.Plant Physiology , 177 (2), 615-632. https://doi.org/10.1104/pp.18.00033

Barkla, B. J., \& Vera-Estrella, R. (2015). Single cell-type comparative metabolomics of epidermal bladder cells from the halophyteMesembryanthemum crystallinum. Frontiers in Plant Science ,6 (June), 1-10. https://doi.org/10.3389/fpls.2015.00435

Barkla, B. J., Vera-Estrella, R., Camacho-Emiterio, J., \& Pantoja, O. (2002). Na+/H+ exchange in the halophyte Mesembryanthemum crystallinum is associated with cellular sites of $\mathrm{Na}+$ storage. Functional Plant Biology , 29 , 1017-1024.

Barkla, B. J., Vera-Estrella, R., \& Pantoja, O. (2012). Protein profiling of epidermal bladder cells from the halophyteMesembryanthemum crystallinum . Proteomics , 12 (18), 2862-2865. https://doi.org/10.1002/pmic.201200152 
Barkla, B. J., Vera-Estrella, R., \& Raymond, C. (2016). Single-cell-type quantitative proteomic and ionomic analysis of epidermal bladder cells from the halophyte model plantMesembryanthemum crystallinum to identify salt-responsive proteins. BMC Plant Biology , 16 (1), 1-10. https://doi.org/10.3389/fpls.2015.00435

Benjamini, Y., \& Hochberg, Y. (1995). Controlling the False Discovery Rate: A Practical and Powerful Approach to Multiple Testing. Journal of the Royal Statistical Society: Series B (Methodological) , 57 (1), 289-300. https://doi.org/10.1111/j.2517-6161.1995.tb02031.x

Böhm, J., Messerer, M., Müller, H. M., Scholz-Starke, J., Gradogna, A., Scherzer, S., Maierhofer, T., Bazihizina, N., Zhang, H., Stigloher, C., Ache, P., Al-Rasheid, K. A. S., Mayer, K. F. X., Shabala, S., Carpaneto, A., Haberer, G., Zhu, J. K., \& Hedrich, R. (2018). Understanding the molecular basis of salt sequestration in epidermal bladder cells ofChenopodium quinoa. Current Biology , 28 (19), 3075-3085.e7. https://doi.org/10.1016/j.cub.2018.08.004

Cheong, B. E., Ho, W. W. H., Biddulph, B., Wallace, X., Rathjen, T., Rupasinghe, T. W. T., Roessner, U., \& Dolferus, R. (2019). Phenotyping reproductive stage chilling and frost tolerance in wheat using targeted metabolome and lipidome profiling. Metabolomics , 15 (11). https://doi.org/10.1007/s11306-019-1606-2

Choi, Y. H., van Spronsen, J., Dai, Y., Verberne, M., Hollmann, F., Arends, I. W. C. E., Witkamp, G. J., \& Verpoorte, R. (2011). Are natural deep eutectic solvents the missing link in understanding cellular metabolism and physiology? Plant Physiology ,156 (4), 1701-1705. https://doi.org/10.1104/pp.111.178426

Dai, Y., van Spronsen, J., Witkamp, G. J., Verpoorte, R., \& Choi, Y. H. (2013). Natural deep eutectic solvents as new potential media for green technology. Analytica Chimica Acta , 766 , 61-68. https://doi.org/10.1016/j.aca.2012.12.019

Desbrosses, G., Steinhauser, D., Kopka, J., \& Michael Udvardi. (2005). Metabolome Analysis using GC-MS. In A. J. Márquez (Ed.), Lotus japonicus Handbook (pp. 165-166). Springer. 10.1007/1-4020-3735-X_17

El-Sadek, A., Balah, M., Romani, A., Ieri, F., Vignolini, P., Salem, E., Mosselhy, N., \& Virtuosi, I. (2017). Allelopathic potential of quinoa (Chenopodium quinoa WILLD.) genotypes on the germination and initial development of some weeds and crops. Egyptian Journal Desert Research , 67 (1), 25-45.

Eustis, A., Murphy, K. M., \& Barrios-Masias, F. H. (2020). Leaf gas exchange performance of ten quinoa genotypes under a simulated heat wave. Plants , 9 (1), 1-15. https://doi.org/10.3390/plants9010081

Falcone, D. L., Ogas, J. P., \& Somerville, C. R. (2004). Regulation of membrane fatty acid composition by temperature in mutants of Arabidopsis with alterations in membrane lipid composition. BMC Plant Biology , 4 , 1-45. https://doi.org/10.1186/1471-2229-4-17

Fan, J., Yu, L., \& Xu, C. (2017). A central role for triacylglycerol in membrane lipid breakdown, fatty acid $\beta$-oxidation, and plant survival under extended darkness. Plant Physiology , 174 (3), 1517-1530. https://doi.org/10.1104/pp.17.00653

FAO. (2018). The future of food and agriculture - Alternative pathways to 2050 . http://www.fao.org/3/I8429EN/i8429en.pdf

Ferdinando Di, M., Brunetti, C., Fini, A., \& Tattini, M. (2012). Flavonoids as Antioxidants in Plants Under Abiotic Stresses. In M. N. V. Prasad \& P. Ahmad (Eds.), Abiotic Stress Responses in Plants: Metabolism, Productivity and Sustainability (pp. 159-179). Springer Science+Business Media. https://doi.org/10.1007/978-1-4614-0634-1

Forman, H. J., Zhang, H., \& Rinna, A. (2009). Glutathione: Overview of its protective roles, measurement, and biosynthesis. Molecular Aspects of Medicine , 30 (1-2), 1-12. https://doi.org/10.1016/j.mam.2008.08.006

Franceschi, V. R., \& Nakata, P. A. (2005). Calcium oxalate in plants: Formation and function. Annual Review of Plant Biology ,56 , 41-71. https://doi.org/10.1146/annurev.arplant.56.032604.144106 
Gómez-Caravaca, A. M., Iafelice, G., Lavini, A., Pulvento, C., Caboni, M. F., \& Marconi, E. (2012). Phenolic compounds and saponins in quinoa samples (Chenopodium quinoa Willd.) grown under different saline and nonsaline irrigation regimens. Journal of Agricultural and Food Chemistry , 60 (18), 4620-4627. https://doi.org/10.1021/jf3002125

Graf, B. L., Poulev, A., Kuhn, P., Grace, M. H., Lila, M. A., \& Raskin, I. (2014). Quinoa seeds leach phytoecdysteroids and other compounds with anti-diabetic properties. Food Chemistry , 163 , 178-185. https://doi.org/10.1016/j.foodchem.2014.04.088

Guy, C., Kaplan, F., Kopka, J., Selbig, J., \& Hincha, D. K. (2008). Metabolomics of temperature stress. Physiologia Plantarum ,132 (2), 220-235. https://doi.org/10.1111/j.1399-3054.2007.00999.x

Hannah, M. A., Wiese, D., Freund, S., Fiehn, O., Heyer, A. G., \& Hincha, D. K. (2006). Natural genetic variation of freezing tolerance in arabidopsis. Plant Physiology , 142 (1), 98-112. https://doi.org/10.1104/pp.106.081141

Higashi, Y., Okazaki, Y., Myouga, F., Shinozaki, K., \& Saito, K. (2015). Landscape of the lipidome and transcriptome under heat stress inArabidopsis thaliana. Scientific Reports , 5 , 1-7. https://doi.org/10.1038/srep10533

Hinojosa, L., Kumar, N., Gill, K. S., Murphy, K. M., \& Crop, D. (2019). Spectral Reflectance Indices and Physiological Parameters in Quinoa under Contrasting Irrigation Regimes. Crop Science, 59 , 1927-1944. https://doi.org/10.2135/cropsci2018.11.0711

Hoekstra, F. A., Golovina, E. A., Tetteroo, F. A. A., \& Wolkers, W. F. (2001). Induction of desiccation tolerance in plant somatic embryos: How exclusive is the protective role of sugars? Cryobiology ,43 (2), 140-150. https://doi.org/10.1006/cryo.2001.2358

Huttunen, E., Noro, K., \& Yang, Z. (1995). Purification and identification of antimicrobial substances produced by twoLactobacillus casei strains. International Dairy Journal ,5 (5), 503-513. https://doi.org/10.1016/0958-6946(95)00030-7

Ibdah, M., Krins, A., Seidlitz, H. K., Heller, W., Strack, D., \& Vogt, T. (2002). Spectral dependence of flavonol and betacyanin accumulation in Mesembryanthemum crystallinum under enhanced ultraviolet radiation. Plant, Cell and Environment, 25 (9), 1145-1154. https://doi.org/10.1046/j.1365-3040.2002.00895.x

Imamura, T., Yasui, Y., Koga, H., Takagi, H., Abe, A., Nishizawa, K., Mizuno, N., Ohki, S., Mizukoshi, H., \& Mori, M. (2020). A novel WD40-repeat protein involved in formation of epidermal bladder cells in the halophyte quinoa. Communications Biology, 3 (1), 1-14. https://doi.org/10.1038/s42003-020-01249-w

Iordachescu, M., \& Imai, R. (2008). Trehalose biosynthesis in response to abiotic stresses. Journal of Integrative Plant Biology ,50 (10), 1223-1229. https://doi.org/10.1111/j.1744-7909.2008.00736.x

Jarvis, D. E., Ho, Y. S., Lightfoot, D. J., Schmöckel, S. M., Li, B., Borm, T. J. A., Ohyanagi, H., Mineta, K., Michell, C. T., Saber, N., Kharbatia, N. M., Rupper, R. R., Sharp, A. R., Dally, N., Boughton, B. A., Woo, Y. H., Gao, G., Schijlen, E. G. W. M., Guo, X., .. Tester, M. (2017). The genome of Chenopodium quinoa .Nature , 542 (7641), 307-312. https://doi.org/10.1038/nature21370

Jenks, M. A., Rashotte, A. M., Tuttle, H. A., \& Feldmann, K. A. (1996). Mutants in Arabidopsis thaliana altered in epicuticular wax and leaf morphology. Plant Physiology , 110 (2), 377-385. https://doi.org/10.1104/pp.110.2.377

Jorge, T. F., Rodrigues, J. A., Caldana, C., Schmist, R., van Dongen, J. T., Thomas-Oate, Antonio, C. (2015). Mass spectrometry-based plant metabolomics: Metabolite response to abiotic stress. Mass Spectrometry Reviews , 35 , 62-649. https://doi.org/10.1002/mas

Jou, Y., Wang, Y. L., \& Yen, H. E. (2007). Vacuolar acidity, protein profile, and crystal composition of epidermal bladder cells of the halophyte Mesembryanthemum crystallinum . Functional Plant Biology , 34 


\section{(4), 353-359. https://doi.org/10.1071/FP06269}

Karimi, S. H., \& Ungar, I. A. (1989). Development of epidermal salt hairs in Atriplex triangularis Willd. in response to salinity, light intensity, and aeration. Botanical Gazette , 150 (1), 68-71. https://doi.org/10.1086/337749

Kiani-Pouya, A., Roessner, U., Jayasinghe, N. S., Lutz, A., Rupasinghe, T., Bazihizina, N., Bohm, J., Alharbi, S., Hedrich, R., \& Shabala, S. (2017). Epidermal bladder cells confer salinity stress tolerance in the halophyte quinoa and Atriplex species. Plant Cell and Environment , 40 (9), 1900-1915. https://doi.org/10.1111/pce.12995

Knudsen, C., Gallage, N. J., Hansen, C. C., Møller, B. L., \& Laursen, T. (2018). Dynamic metabolic solutions to the sessile life style of plants. Natural Product Reports , 35 (11), 1140-1155. https://doi.org/10.1039/c8np00037a

Kumar, A., \& Bachhawat, A. K. (2012). Pyroglutamic acid: Throwing light on a lightly studied metabolite. Current Science, 102 (2), 288-297.

Larkindale, J., \& Huang, B. (2004). Changes of lipid composition and saturation level in leaves and roots for heat-stressed and heat-acclimated creeping bentgrass (Agrostis stolonifera).Environmental and Experimental Botany , 51 , 57-67. https://doi.org/10.1016/S0098-8472(03)00060-1

Liphschitz, N., \& Waisel, Y. (1982). Adaptation of plants to saline environments: salt excretion and glandular structure. In D. N. Sen \& K. S. Rajpurohit (Eds.), Tasks for vegetation science (Vol. 2, pp. 197-214). https://doi.org/10.1007/978-94-009-8037-2_14

LoPresti, E. F. (2014). Chenopod salt bladders deter insect herbivores.Oecologia , 174 (3), 921-930. https://doi.org/10.1007/s00442-013-2827-0

Madl, T., Sterk, H., Mittelbach, M., \& Rechberger, G. N. (2006). Tandem mass spectrometric analysis of a complex triterpene saponin mixture ofChenopodium quinoa. Journal of the American Society for Mass Spectrometry , 17 , 795-806. https://doi.org/10.1016/j.jasms.2006.02.013

Miller, G., Suzuki, N., Ciftci-Yilmaz, S., \& Mittler, R. (2010). Reactive oxygen species homeostasis and signalling during drought and salinity stresses. Plant, Cell and Environment , 33 (4), 453-467. https://doi.org/10.1111/j.1365-3040.2009.02041.x

Nishizawa, A., Yabuta, Y., \& Shigeoka, S. (2008). Galactinol and raffinose constitute a novel function to protect plants from oxidative damage. Plant Physiology , 147 (3), 1251-1263. https://doi.org/10.1104/pp.108.122465

Oh, D. H., Barkla, B. J., Vera-Estrella, R., Pantoja, O., Lee, S. Y., Bohnert, H. J., \& Dassanayake, M. (2015). Cell type-specific responses to salinity - the epidermal bladder cell transcriptome ofMesembryanthemum crystallinum . New Phytologist ,207 (3), 627-644. https://doi.org/10.1111/nph.13414

Orsini, F., Accorsi, M., Gianquinto, G., Dinelli, G., Antognoni, F., Carrasco, K. B. R., Martinez, E. A., Alnayef, M., Marotti, I., Bosi, S., \& Biondi, S. (2011). Beyond the ionic and osmotic response to salinity in Chenopodium quinoa : Functional elements of successful halophytism. Functional Plant Biology , 38 (10), 818-831. https://doi.org/10.1071/FP11088

Paśko, P., Sajewicz, M., Gorinstein, S., \& Zachwieja, Z. (2008). Analysis of selected phenolic acids and flavonoids in Amaranthus cruentus and Chenopodium quinoa seeds and sprouts by HPLC.Acta Chromatographica , 20 (4), 661-672. https://doi.org/10.1556/AChrom.20.2008.4.11

Pereira, E., Encina-Zelada, C., Barros, L., Gonzales-Barron, U., Cadavez, V., \& C.F.R. Ferreira, I. (2019). Chemical and nutritional characterization of Chenopodium quinoa Willd (quinoa) grains: A good alternative to nutritious food. Food Chemistry , 280 , 110-114. https://doi.org/10.1016/j.foodchem.2018.12.068 
Pulvento, C., Riccardi, M., Lavini, A., Iafelice, G., Marconi, E., \& D’Andria, R. (2012). Yield and quality characteristics of quinoa grown in open field under different saline and non-saline irrigation regimes. Journal of Agronomy and Crop Science, 198 (4), 254-263.

Repo-Carrasco-Valencia, R., Hellström, J. K., Pihlava, J. M., \& Mattila, P. H. (2010). Flavonoids and other phenolic compounds in Andean indigenous grains: Quinoa (Chenopodium quinoa), kañiwa (Chenopodium pallidicaule) and kiwicha (Amaranthus caudatus ). Food Chemistry , 120 (1), 128-133. https://doi.org/10.1016/j.foodchem.2009.09.087

Repo-Carrasco, R., Espinoza, C., \& Jacobsen, S. E. (2003). Nutritional value and use of the andean crops quinoa (Chenopodium quinoa) and kañiwa (Chenopodium pallidicaule). Food Reviews International , 19 (1-2), 179-189. https://doi.org/10.1081/FRI-120018884

Roessner, U., Wagner, C., Kopka, J., Trethewey, R. N., \& Willmitzer, L. (2000). Simultaneous analysis of metabolites in potato tuber by gas chromatography-mass spectrometry. Plant Journal , 23 (1), 131-142. https://doi.org/10.1046/j.1365-313X.2000.00774.x

Roman, V. J., den Toom, L. A., Castro Gamiz, C., van der Pijl, N., Visser, R. G. F., van Loo, E. N., \& van der Linden, C. G. (2020). Differential responses to salt stress in ion dynamics, growth and seed yield of European quinoa varieties. Environmental and Experimental Botany , 177 (February), 104146. https://doi.org/10.1016/j.envexpbot.2020.104146

Schmöckel, S. M., Lightfoot, D. J., Razali, R., Tester, M., \& Jarvis, D. E. (2017). Identification of Putative Transmembrane Proteins Involved in Salinity Tolerance in Chenopodium quinoa by Integrating Physiological Data, RNAseq, and SNP Analyses. Frontiers in Plant Science , 8 (June), 1-12. https://doi.org/10.3389/fpls.2017.01023

Shabala, L., Mackay, A., Tian, Y., Jacobsen, S. E., Zhou, D., \& Shabala, S. (2012). Oxidative stress protection and stomatal patterning as components of salinity tolerance mechanism in quinoa (Chenopodium quinoa). Physiologia Plantarum , 146 (1), 26-38. https://doi.org/10.1111/j.1399-3054.2012.01599.x

Shepherd, T., \& Griffiths, D. W. (2006). The effects of stress on plant cuticular waxes. New Phytologist , 171 (3), 469-499. https://doi.org/10.1111/j.1469-8137.2006.01826.x

Stikić, R. I., Milinčić, D. D., Kostić, A., Jovanović, Z. B., Gašić, U. M., Tešić, Ž. L., Djordjević, N. Z., Savić, S. K., Czekus, B. G., \& Pešić, M. B. (2020). Polyphenolic profiles, antioxidant, and in vitro anticancer activities of the seeds of Puno and Titicaca quinoa cultivars. Cereal Chemistry , 97 (3), 626-633. https://doi.org/10.1002/cche.10278

Szabados, L., \& Savouré, A. (2010). Proline: a multifunctional amino acid. Trends in Plant Science , 15 (2), 89-97. https://doi.org/10.1016/j.tplants.2009.11.009

Taira, J., Tsuchida, E., Katoh, M. C., Uehara, M., \& Ogi, T. (2015). Antioxidant capacity of betacyanins as radical scavengers for peroxyl radical and nitric oxide. Food Chemistry , 166 , 531-536. https://doi.org/10.1016/j.foodchem.2014.05.102

Tang, Y., Li, X., Chen, P. X., Zhang, B., Hernandez, M., Zhang, H., Marcone, M. F., Liu, R., \& Tsao, R. (2015). Characterisation of fatty acid, carotenoid, tocopherol/tocotrienol compositions and antioxidant activities in seeds of three Chenopodium quinoa Willd. genotypes. In Food Chemistry (Vol. 174). Elsevier Ltd. https://doi.org/10.1016/j.foodchem.2014.11.040

Tang, Y., Li, X., Zhang, B., Chen, P. X., Liu, R., \& Tsao, R. (2015). Characterisation of phenolics, betanins and antioxidant activities in seeds of three Chenopodium quinoa Willd. genotypes. Food Chemistry , 166 , 380-388. https://doi.org/10.1016/j.foodchem.2014.06.018

Tanksley, S. D., \& McCouch, S. R. (1997). Seed banks and molecular maps: Unlocking genetic potential from the wild the narrow genetic base of crop plants. Science , 277, 1063-1066. https://doi.org/10.1126/science.277.5329.1063 
Tsugawa, H., Ikeda, K., Takahashi, M., Satoh, A., Mori, Y., Uchino, H., Okahashi, N., Yamada, Y., Tada, I., Bonini, P., Higashi, Y., Okazaki, Y., Zhou, Z., Zhu, Z. J., Koelmel, J., Cajka, T., Fiehn, O., Saito, K., Arita, M., \& Arita, M. (2020). A lipidome atlas in MS-DIAL 4.Nature Biotechnology, 38 (10), 1159-1163. https://doi.org/10.1038/s41587-020-0531-2

Vogt, T., Ibdah, M., Schmidt, J., Wray, V., Nimtz, M., \& Strack, D. (1999). Light-induced betacyanin and flavonol accumulation in bladder cells of Mesembryanthemum crystallinum. Phytochemistry ,52 (4), 583-592. https://doi.org/10.1016/S0031-9422(99)00151-X

Wagner, G. J. (1991). Secreting Glandular Trichomes: More than Just Hairs. Plant Physiology , 96 (3), 675-679. https://doi.org/10.1104/pp.96.3.675

Wybraniec, S., Stalica, P., Spórna, A., Nemzer, B., Pietrzkowski, Z., \& Michałowski, T. (2011). Antioxidant activity of betanidin: Electrochemical study in aqueous media. Journal of Agricultural and Food Chemistry , 59 (22), 12163-12170. https://doi.org/10.1021/jf2024769

Zhu, F., Yuan, C., Gang, F., Yang, C., Wu, W., \& Zhang, J. (2018). Bioassay-Guided Isolation of Antifungal Compounds from Disporopsis aspersa (Hua) Engl. ex Diels against Pseudoperonospora cubensisand Phytophthora infestans. Chemistry and Biodiversity,15 (7). https://doi.org/10.1002/cbdv.201800090

Zhu, N., Kikuzaki, H., Vastano, B. C., Nakatani, N., Karwe, M. V., Rosen, R. T., \& Ho, C. T. (2001). Ecdysteroids of quinoa seeds (Chenopodium quinoa Willd.). Journal of Agricultural and Food Chemistry, 49 (5), 2576-2578. https://doi.org/10.1021/jf0014462

Zou, C., Chen, A., Xiao, L., Muller, H. M., Ache, P., Haberer, G., Zhang, M., Jia, W., Deng, P., Huang, R., Lang, D., Li, F., Zhan, D., Wu, X., Zhang, H., Bohm, J., Liu, R., Shabala, S., Hedrich, R., .. Zhang, H. (2017). A high-quality genome assembly of quinoa provides insights into the molecular basis of salt bladder-based salinity tolerance and the exceptional nutritional value. Cell Research ,27 (11), 1327-1340. https://doi.org/10.1038/cr.2017.124

Zurita-Silva, A., Fuentes, F., Zamora, P., Jacobsen, S. E., \& Schwember, A. R. (2014). Breeding quinoa (Chenopodium quinoaWilld.): Potential and perspectives. Molecular Breeding ,34 (1), 13-30. https://doi.org/10.1007/s11032-014-0023-5

Table1: Identified secondary metabolites in EBCs of quinoa.

\begin{tabular}{|c|c|c|c|c|c|}
\hline $\mathrm{RT}(\min )$ & Formula & $\mathrm{UV}_{\max }(\mathrm{nm})$ & Tentative identification & {$[\mathrm{M}+\mathrm{H}]+(\mathrm{m} / \mathrm{z})$} & MS/MS fragment \\
\hline & & & Flavonoids & & \\
\hline 38.47 & $\mathrm{C} 26 \mathrm{H} 26 \mathrm{O} 17$ & 256 & Quercetin pentosyl-glucuronide & 611.12341 & $\operatorname{MS}^{2}[611.1]: 47 !$ \\
\hline 39.58 & $\mathrm{C} 21 \mathrm{H} 18 \mathrm{O} 13$ & 256 & Quercetin glucuronide & 479.08155 & $\operatorname{MS2}[479.1]: 303.0$ \\
\hline 40.11 & C27H30O16 & 256 & Quercetin rhamnosyl-glucoside & 611.1601 & $\operatorname{MS}^{2}[611.1]: 465$. \\
\hline 44.07 & $\mathrm{C} 21 \mathrm{H} 18 \mathrm{O} 2$ & 264 & Kaempferol glucuronide & 463.0864 & $\operatorname{MS2}[463.1]: 287.0$ \\
\hline 50.43 & $\mathrm{C} 30 \mathrm{H} 26 \mathrm{O} 13$ & n.d. & Kaempferol coumaroyl-glucoside & 595.14337 & MS2[595.1]: 309 \\
\hline 45.27 & $\mathrm{C} 28 \mathrm{H} 32 \mathrm{O} 16$ & 254 & Isorhamnetin rhamnosyl-hexoside & 625.1755 & $\operatorname{MS2}[625.1]: 479$ \\
\hline 45.53 & $\mathrm{C} 22 \mathrm{H} 22 \mathrm{O} 12$ & n.d. & Isorhamnetin hexoside & 479.11771 & $\operatorname{MS} 2[479.1]: 317.0$ \\
\hline 45.89 & $\mathrm{C} 22 \mathrm{H} 20 \mathrm{O} 13$ & 254 & Isorhamnetin glucoronide & 493.0967 & $\operatorname{MS} 2[493.1]: 317.0$ \\
\hline 48.79 & $\mathrm{C} 28 \mathrm{H} 32 \mathrm{O} 16$ & 256 & Rhamnetin rhamnosyl-hexosid & 625.17535 & $\operatorname{MS2}[625.1]: 479$ \\
\hline 49.65 & $\mathrm{C} 22 \mathrm{H} 20 \mathrm{O} 13$ & 256 & $\begin{array}{l}\text { Rhamnetin glucuronide } \\
\text { Betacyanins }\end{array}$ & 493.09695 & MS2[493.1]: 317.0 \\
\hline 9.816 & $\mathrm{C} 30 \mathrm{H} 34 \mathrm{~N} 2 \mathrm{O} 19$ & 534 & Amaranthin & 727.18164 & MS2[727.1]: 389.0 \\
\hline 12.61 & $\mathrm{C} 24 \mathrm{H} 26 \mathrm{~N} 2 \mathrm{O} 13$ & 534 & $\begin{array}{l}\text { Betanin } \\
\text { Sterol }\end{array}$ & 551.15033 & MS2[551.1]: 389.1 \\
\hline 43.62 & $\mathrm{C} 27 \mathrm{H} 44 \mathrm{O} 7$ & n.d & $\begin{array}{l}\text { Ecdysterone } \\
\text { Saponins }\end{array}$ & 481.31531 & $\operatorname{MS} 2[481.3]: 463$ \\
\hline 53.81 & C47H70O21 & n.d & Saponin I & $988.47205[\mathrm{M}+\mathrm{NH} 4]^{+}$ & MS2[988.4]: 809 \\
\hline
\end{tabular}




\begin{tabular}{|c|c|c|c|c|c|}
\hline $\mathrm{RT}(\min )$ & Formula & $\mathrm{UV}_{\max }(\mathrm{nm})$ & Tentative identification & {$[\mathrm{M}+\mathrm{H}]+(\mathrm{m} / \mathrm{z})$} & MS/MS fragment \\
\hline 56.01 & $\mathrm{C} 47 \mathrm{H} 70 \mathrm{O} 20$ & n.d & Saponin II & $972.47736[\mathrm{M}+\mathrm{NH} 4]^{+}$ & MS2[972.4]: 747 \\
\hline 56.505 & C47H70O21 & n.d. & $\begin{array}{l}\text { Saponin II } \\
\text { Hydrocinnamic acids }\end{array}$ & $972.47833[\mathrm{M}+\mathrm{NH} 4]^{+}$ & MS2[972.4]: 747 \\
\hline 16.721 & $\mathrm{C} 15 \mathrm{H} 18 \mathrm{O} 8$ & n.d & Coumaroyl-glucoside & $344.1336[\mathrm{M}+\mathrm{NH} 4]^{+}$ & MS2[344.1]: 309 \\
\hline 22.34 & C16H20O9 & n.d & Feruloyl-glucoside & $374,1442[\mathrm{M}+\mathrm{NH} 4]^{+}$ & MS2[374.1]: 212 \\
\hline 26.37 & C17H22O10 & n.d & Sinapoyl-glucoside & $404.15482[\mathrm{M}+\mathrm{NH} 4]^{+}$ & $\operatorname{MS} 2[404.1]: 225 .($ \\
\hline
\end{tabular}

\section{Figure legends}

Figure 1. Epidermal Bladder Cells (EBCs). EBCs (A) on quinoa leave surface and (B) on stem. (C) EBCs consist of highly vacuolated bladder cells attached to a narrow short stalk.

Figure 2: Response of C. quinoa to abiotic stresses.

(A) Change in plant height; (B) biomass, (C) total leaf area and (D) the Na concentration. Significant differences were analysed using ANOVA followed by Tukey HSD. Significantly different samples are indicated by letters. HL: high-light, WD: water deficit. E) Photographs of representative plant exposed to abiotic stresses. Plants were photographed with the same camera setting using a black velvet background, for this figure the pictures were cropped into one image and background removed. Scale bar indicates $10 \mathrm{~cm}$.

Figure 3: Primary metabolome analysis of quinoa EBCs under stress treatment. 64 primary metabolites, categorized in 5 groups, were measured by GC-MS. (A) PCA Scoresplot displaying the similarities and dissimilarities between metabolite profiles of EBCs of all stressed plants. Plots generated by MetaboAnalyst. Water deficit treatment is not shown as statistical analysis could not be performed on just two biological replicates. (B) The bar chart represents the percentage of changed metabolites per category and stress treatment. (C) Log2-fold changes of primary metabolites for heat, cold and high-light treated quinoa plants. Fold changes were calculated by dividing the concentration of the stress-treated plants to the concentration of the control plants after six days, then log2-transformed. Significance of difference was determined by Benjamini and Hochberg method with false discovery rate (FDR)-adjusted $p$-value of 0.05 as the cut-off and marked by an asteriks. Orange significant decrease, Greensignificant increase. There were three biological replicates $(\mathrm{n}=3)$. The data is representative of two experimental replicates.

Figure 4: Lipid analysis of quinoa EBCs under stress treatment . 240 lipids, categorized in four major groups and $>4000$ untargeted features were measured by LC-MS. (A) PCA Scoresplot displaying the similarities and dissimilarities between targeted lipid profiles of EBCs of all stressed plants. Plots generated by MetaboAnalyst. (B) PCA Scoresplot displaying the similarities and dissimilarities between untargeted lipid profiles of EBCs of all stressed plants. Plots generated by MetaboAnalyst. (C) $\log _{2}$-fold changes of some targeted lipids (showing a significant change) for heat and salt-treated quinoa plants. Fold changes were calculated by dividing the concentration of the stress-treated plants to the concentration of the control plants after six days, then $\log _{2}$-transformed. Significance of difference was determined by Benjamini and Hochberg method with false discovery rate (FDR)-adjusted $p$-value of 0.05 as the cut-off and marked by an asteriks. Orange significant decrease, Greensignificant increase. There were three biological replicates $(\mathrm{n}=$ $3)$. The data is representative of two experimental replicates.

Figure 5: Secondary metabolome analysis of quinoa EBCs under stress treatment. 1600 features analysed by untargeted LC-MS. 19 features identified and categorized in 5 groups. (A) PCA Scoresplot displaying the similarities and dissimilarities between untageted secondary metabolite profiles of EBCs of all stressed plants. Plots generated by MetaboAnalyst. (B) Log2-fold changes of the identified secondary metabolites for heat, cold, high-light, water deficit and salt-treated quinoa plants. Fold changes were calculated by dividing the concentration of the stress-treated plants to the concentration of the control plants after six days, then log2-transformed. Significance of difference was determined by Benjamini and Hochberg 
method with false discovery rate (FDR)-adjusted $p$-value of 0.05 as the cut-off and marked by an asteriks. There were three biological replicates $(n=3)$. The data is representative of three experimental replicates.

\section{Supplementary Figures Legends}

Supplementary Figure 1: Primary metabolome analysis of quinoa EBCs under stress treatment. PCA Biplot displaying features influencing the stress treated sample. Plots generated by MetaboAnalyst. Water deficit treatment is not shown as statistical analysis could not be performed on just two biological replicates. There were three biological replicates $(n=3)$. The data is representative of two experimental replicates.

Supplementary Figure 2: Microscopy images of bladders from plants under A) control; B) heat; C) cold; D) high-light; E) water deficit and F) salt treatment. Scale bar indicates $1000 \mu \mathrm{m}$. Concentration of G) Na and $\mathrm{H}) \mathrm{K}$ in bladders of quinoa.

\section{Supplementary Tables}

Supplementary Table S1: List of primary metabolites detected in C. quinoa

Supplementary Table S2: List of targeted lipids detected in C. quinoa

Supplementary Table S3: List of untargeted lipids detected in C. quinoa

Supplementary Table S4: List of secondary metabolites detected in

C. quinoa
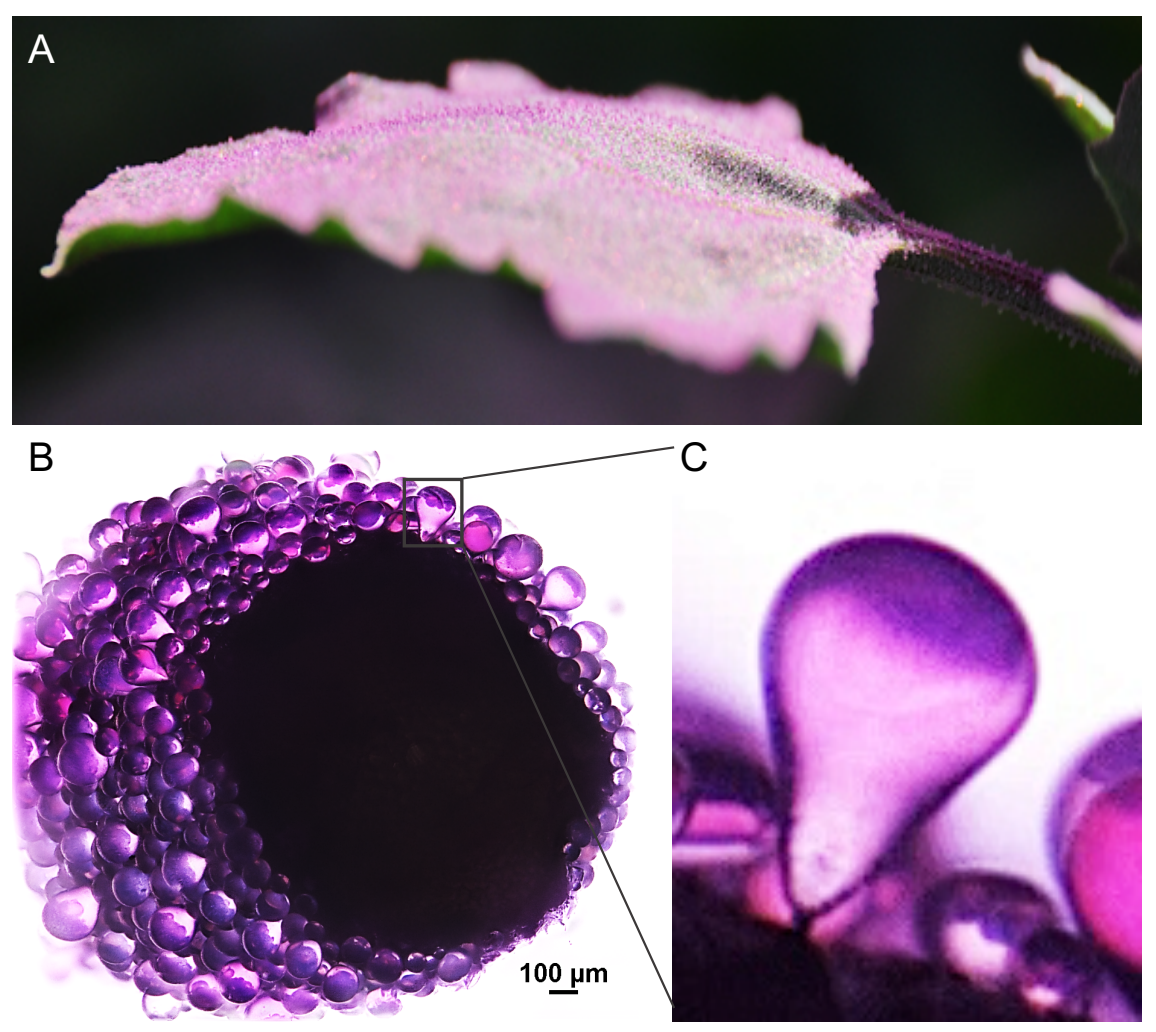

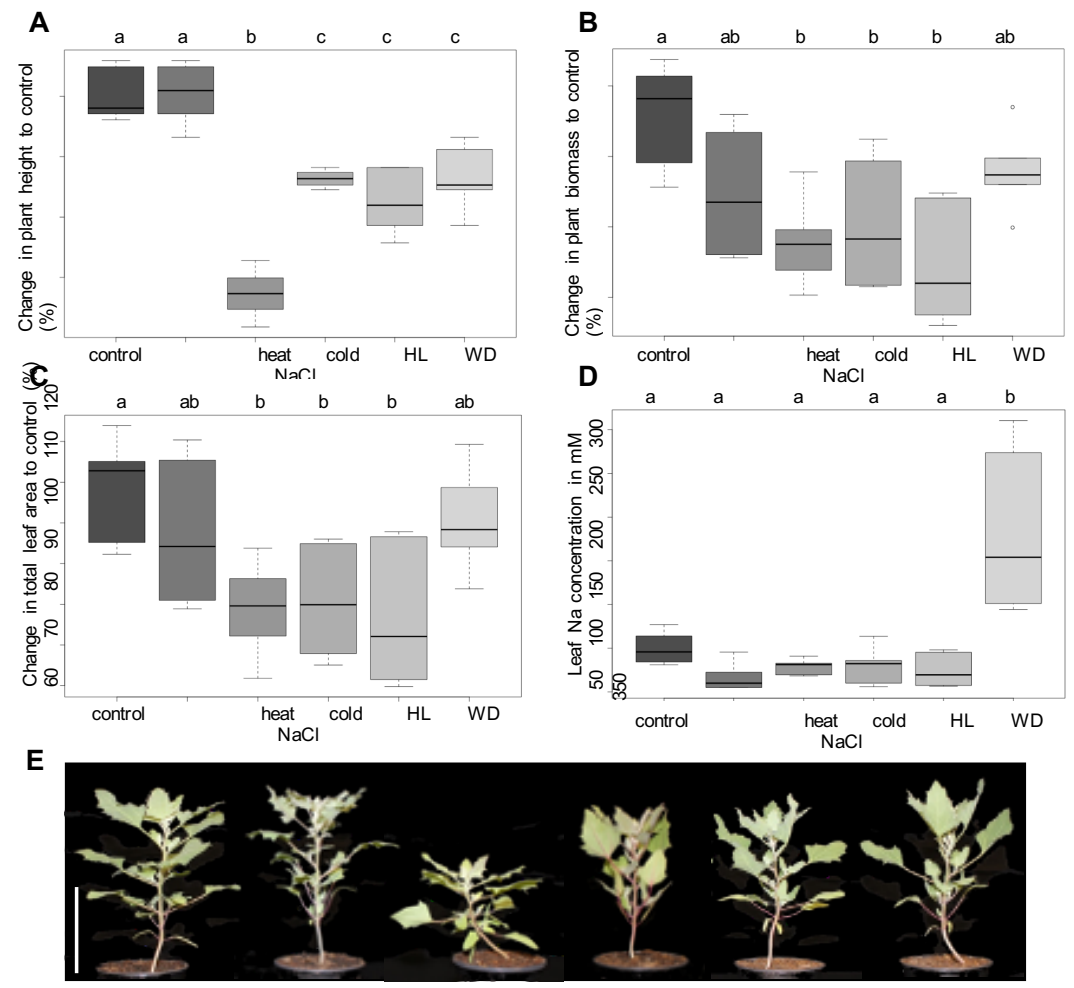


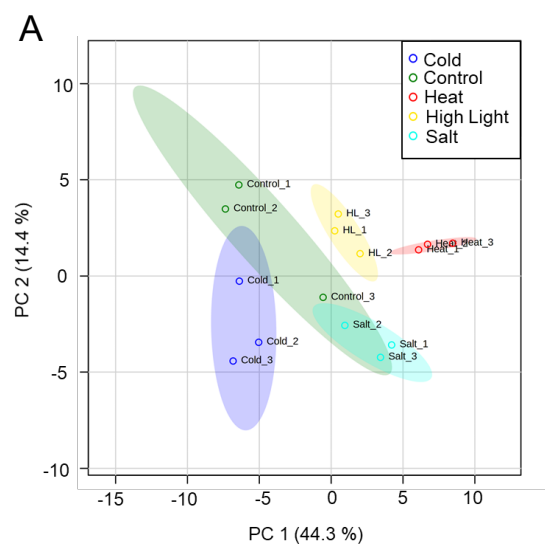

B

C
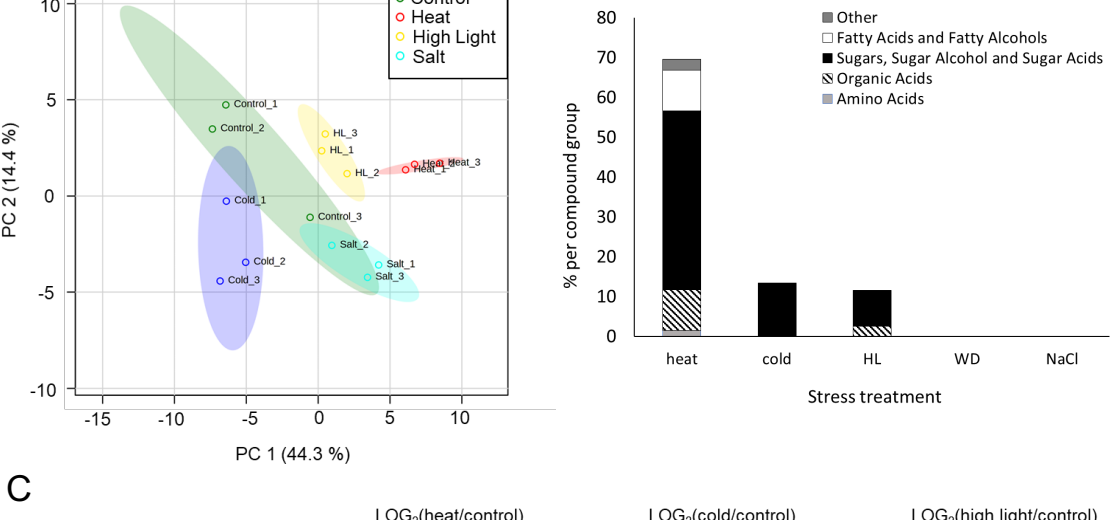

$\mathrm{LOG}_{2}$ (cold/control)

$\mathrm{LOG}_{2}$ (high light/control)
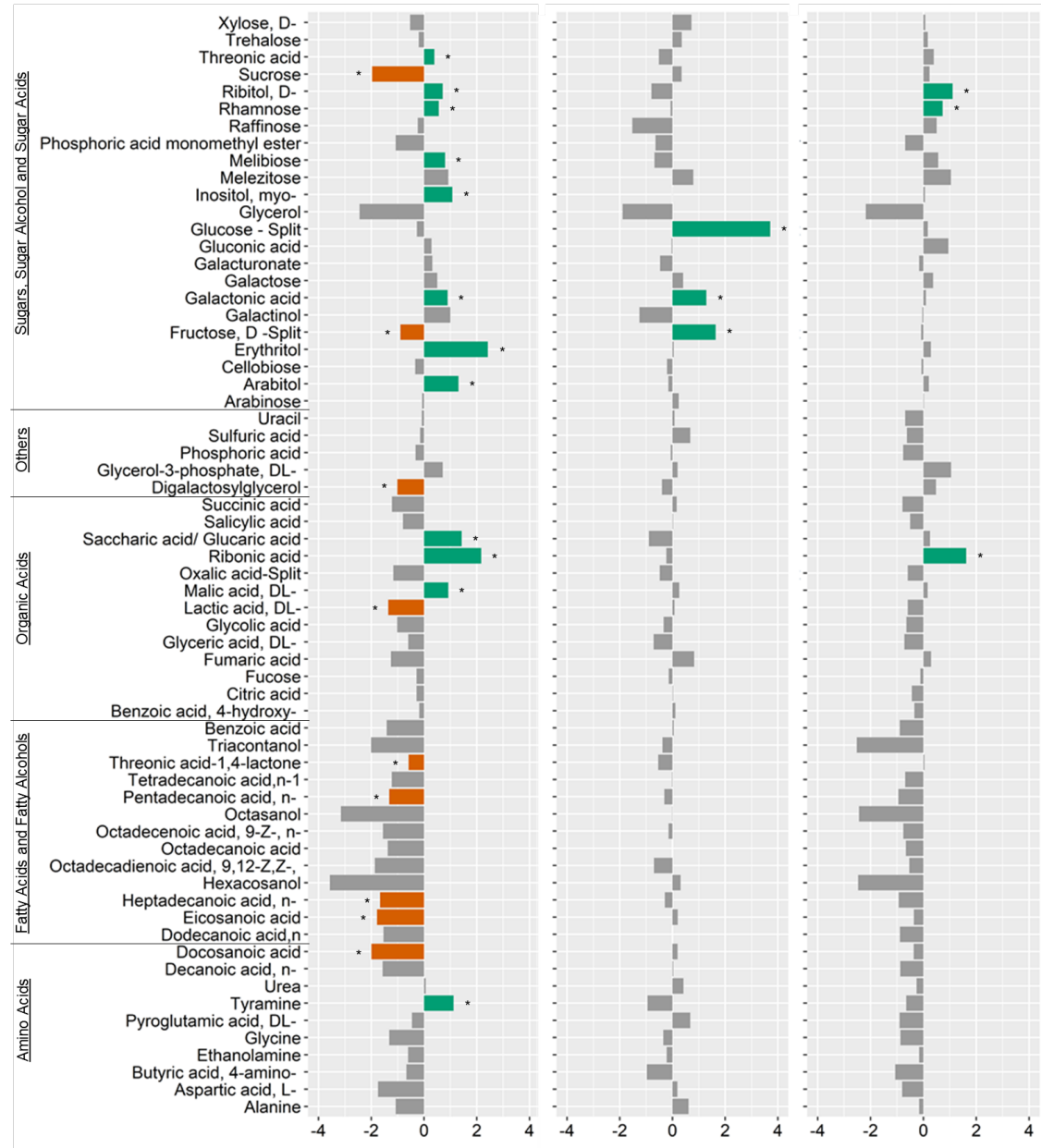
A

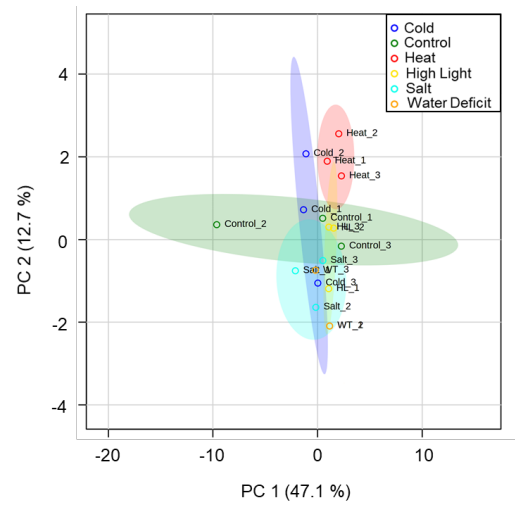

C

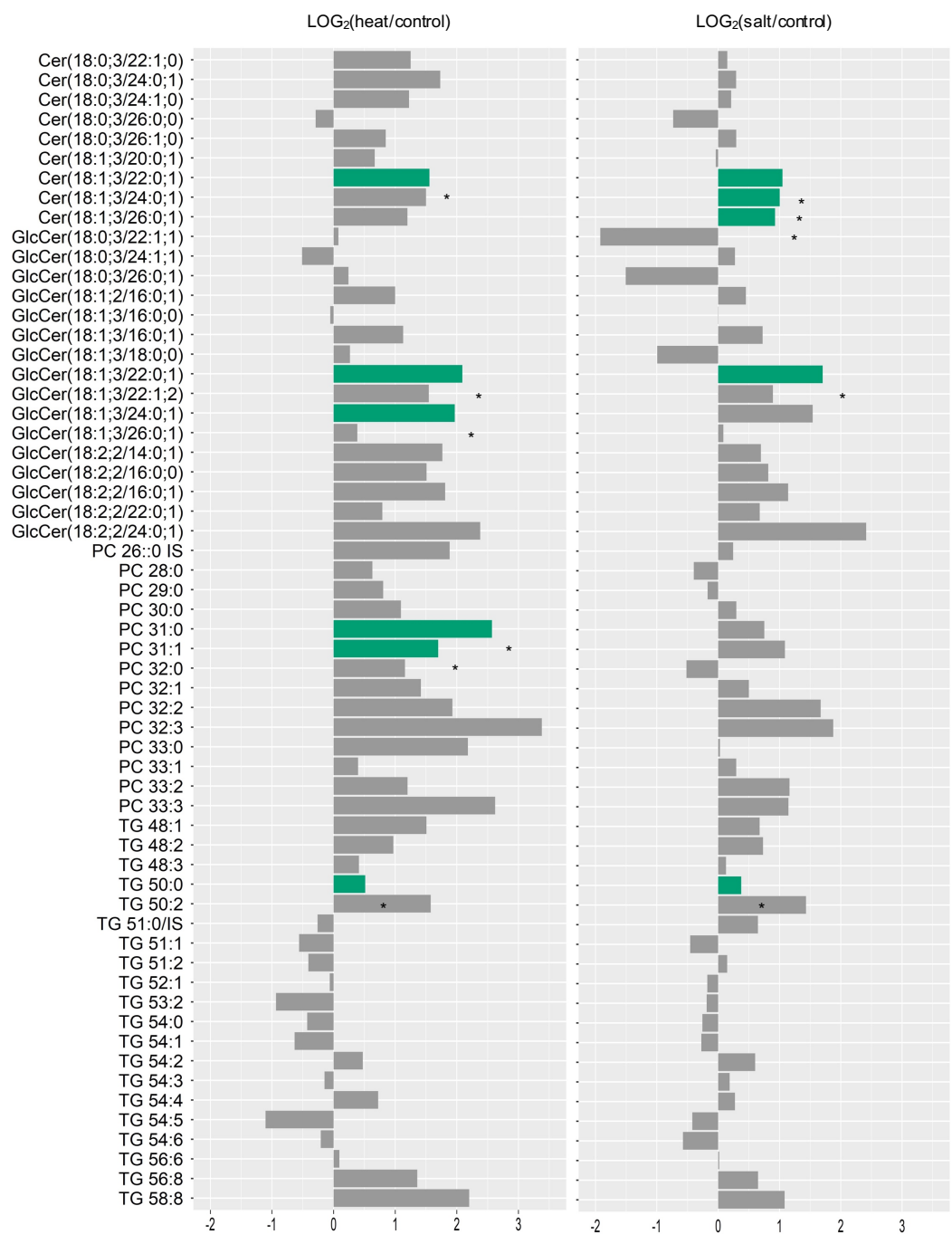

B

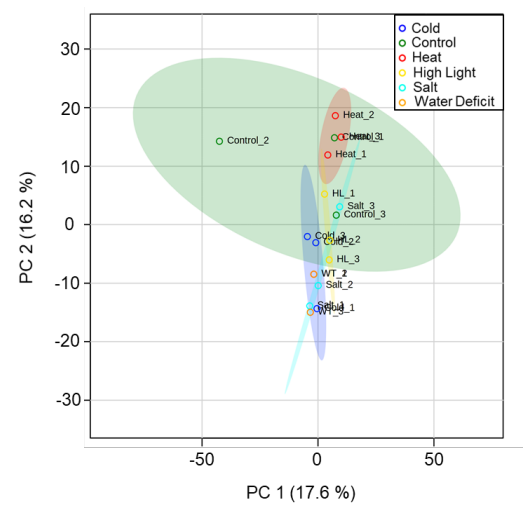

$\mathrm{LOG}_{2}$ (salt/control) 


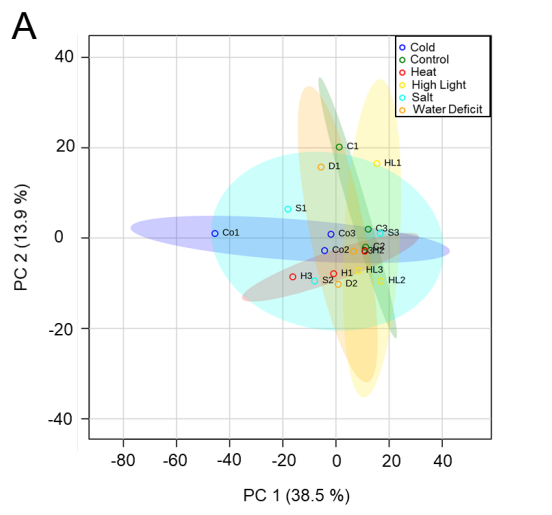

B

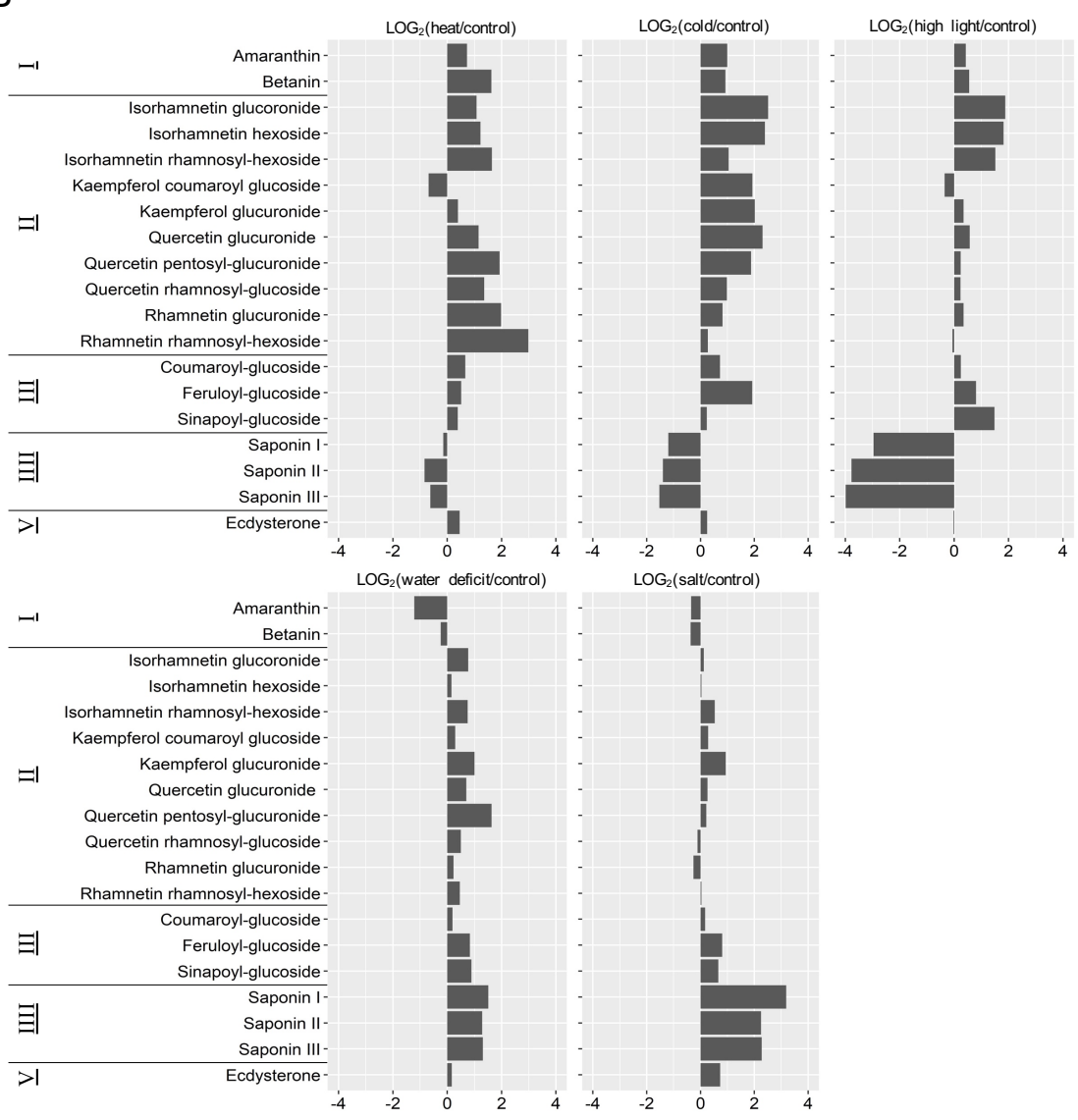

